\title{
Evidence-Based Use of Levothyroxine/ Liothyronine Combinations in Treating Hypothyroidism: A Consensus Document
}

\author{
Jacqueline Jonklaas $^{a}$ Antonio C. Bianco ${ }^{b}$ Anne R. Cappolac Francesco S. Celi ${ }^{d}$ \\ Eric Fliers ${ }^{e}$ Heike Heuer ${ }^{f}$ Elizabeth A. McAninch ${ }^{g}$ Lars C. Moeller ${ }^{f}$ \\ Birte Nygaard $^{\mathrm{h}}$ Anna M.Sawka' Torquil Watt ${ }^{\mathrm{j}}$ Colin M. Dayank \\ ${ }^{a}$ Division of Endocrinology, Georgetown University, Washington, DC, USA; ${ }^{b}$ Section of Adult and Pediatric \\ Endocrinology and Metabolism, University of Chicago, Chicago, IL, USA; 'Division of Endocrinology, Diabetes, \\ and Metabolism, Perelman School of Medicine, University of Pennsylvania, Philadelphia, PA, USA; ${ }^{\text {Division of }}$ \\ Endocrinology, Diabetes and Metabolism, Virginia Commonwealth University, Richmond, VA, USA; ${ }^{\text {eDepartment of }}$ \\ Endocrinology and Metabolism, Amsterdam Gastroenterology Endocrinology Metabolism, Amsterdam University \\ Medical Center, Amsterdam, The Netherlands; ${ }^{\mathrm{f} D e p a r t m e n t}$ of Endocrinology, Diabetes and Metabolism, University \\ Duisburg-Essen, Essen, Germany; ${ }^{9}$ Division of Endocrinology, Rush University, Chicago, IL, USA; ${ }^{\text {h Center for }}$ \\ Endocrinology and Metabolism, Department of Internal Medicine, Herlev and Gentofte Hospitals, Herlev, Denmark; \\ 'Division of Endocrinology, University Health Network and University of Toronto, Toronto, ON, Canada; ${ }^{\text {'Department }}$ \\ of Endocrinology, Copenhagen University Hospital Rigshospitalet, Copenhagen, Denmark; ${ }^{k}$ Thyroid Research \\ Group, School of Medicine, Cardiff University, Cardiff, UK
}

\section{Keywords}

Hypothyroidism · Levothyroxine · Liothyronine ·

Combination therapy · Clinical trial · Patient-reported outcomes

\section{Abstract \\ Background: Fourteen clinical trials have not shown a con- sistent benefit of combination therapy with levothyroxine (LT4) and liothyronine (LT3). Despite the publication of these}

Based on a Joint American Thyroid Association (ATA)/British Thyroid Association (BTA)/European Thyroid Association (ETA) Symposium held in London, UK and Chicago, IL, USA on Sunday, November 3, 2019. This article is simultaneously published in Thyroid (DOI: 10.1089/ thy.2020.0720).

karger@karger.com www.karger.com/etj Karger\% (c) 2021 European Thyroid Association (published by S. Karger AG, Basel), Mary Ann Liebert, Inc. and the American Thyroid Association trials, combination therapy is widely used and patients reporting benefit continue to generate patient and physician interest in this area. Recent scientific developments may provide insight into this inconsistency and guide future studies. Methods: The American Thyroid Association (ATA), British Thyroid Association (BTA), and European Thyroid Association (ETA) held a joint conference on November 3, 2019 (livestreamed between Chicago and London) to review new basic science and clinical evidence regarding combination therapy with presentations and input from 12 content ex-
Jacqueline Jonklaas

Division of Endocrinology, Georgetown University 4000 Reservoir Road, NW

Washington, DC 20007 (USA)

jonklaaj@georgetown.edu

Colin M. Dayan

Thyroid Research Group

School of Medicine, Cardiff University

C2 Link, Heath Park, Cardiff CF14 4XN (UK)

DayanCM@ cardiff.ac.uk 
perts. After the presentations, the material was synthesized and used to develop Summary Statements of the current state of knowledge. After review and revision of the material and Summary Statements, there was agreement that there was equipoise for a new clinical trial of combination therapy. Consensus Statements encapsulating the implications of the material discussed with respect to the design of future clinical trials of LT4/LT3 combination therapy were generated. Authors voted upon the Consensus Statements. Iterative changes were made in several rounds of voting and after comments from ATA/BTA/ETA members. Results: Of 34 Consensus Statements available for voting, 28 received at least $75 \%$ agreement, with 13 receiving 100\% agreement. Those with $100 \%$ agreement included studies being powered to study the effect of deiodinase and thyroid hormone transporter polymorphisms on study outcomes, inclusion of patients dissatisfied with their current therapy and requiring at least $1.2 \mu \mathrm{g} / \mathrm{kg}$ of LT4 daily, use of twice daily LT3 or preferably a slow-release preparation if available, use of patientreported outcomes as a primary outcome (measured by a tool with both relevant content validity and responsiveness) and patient preference as a secondary outcome, and utilization of a randomized placebo-controlled adequately powered double-blinded parallel design. The remaining statements are presented as potential additional considerations. Discussion: This article summarizes the areas discussed and presents Consensus Statements to guide development of future clinical trials of LT4/LT3 combination therapy. The results of such redesigned trials are expected to be of benefit to patients and of value to inform future thyroid hormone replacement clinical practice guidelines treatment recommendations.

(c) 2021 European Thyroid Association (published by S. Karger AG, Basel), Mary Ann Liebert, Inc. and the American Thyroid Association

\section{Introduction}

Endocrinologists are frequently asked to consult on adult patients with hypothyroidism taking levothyroxine (LT4) who are dissatisfied with their therapy. Once other nonthyroid-related causes of these symptoms have been fully excluded, the patient and their physician may wish to explore alternative therapies for optimization of health and well-being. However, the use of combination therapy with both LT4 and liothyronine (LT3) remains highly controversial with conflicting results from published clinical trials [1], with two studies showing benefit in most measures and two showing benefit in some measures.

Combination Therapy Consensus

Statement
Recent scientific studies have provided new mechanistic insight into issues such as the complex relationship between serum and tissue thyroid hormone (TH) levels [1], providing a rationale for reconsideration of the design of future LT4/LT3 combination therapy clinical trials by incorporating features that might increase the likelihood of showing efficacy. Thus, our aim in this consensus document was that consideration of mechanism might provide a path toward better designed trials, also focusing on clinically relevant outcomes, including patient-centered outcomes.

The American Thyroid Association (ATA), British Thyroid Association (BTA), and European Thyroid Association (ETA) held a joint conference on November 3, 2019 (live streamed between Chicago and London) to review this new evidence with presentations and input from 12 leaders in the field followed by local workshops in Chicago and London. The 12 individuals were selected based on their content expertise in basic, translational, and clinical aspects of TH therapy for hypothyroidism. To incorporate input from as many relevant stakeholders as possible, the presenters and moderators included endocrinologists, an epidemiologist, a psychologist, basic scientists, translational scientists, and two patient representatives. This article summarizes the areas discussed and presents a position statement to guide future clinical trials of LT4/LT3 combination therapy.

\section{Methods}

Following the presentations, the associated question-and-answer periods, and the local workshops, the material available was broken down into nine topics. Two authors (J.J. and C.M.D.) then each summarized the content and discussion for half of these topic areas, and then combined the material. This synthesis of material also included formulating Summary Statements to encapsulate the material, and generation of Consensus Statements to capture the direction suggested by the material for the design of future clinical trials of LT4/LT3 combination therapy. The resulting document was then reviewed by the remaining 10 authors. After the conference and during the review process, 2 additional topics emerged based on author feedback (Topics 4 and 9), which had been covered, in part, within the initial topics, thus bringing the total number of topics to 11 . Topic 11 did not relate to future clinical trials and no Consensus Statements were generated for this topic.

For the Consensus Statements, the authors were provided with these in tabular form and were asked to vote yes or no as to whether they agreed with the statement or not. They were also asked to provide comments regarding each of the statements as desired. The consensus document, Summary Statements, and Consensus Statements were then modified and returned to the writing group for further adjustments and suggestions. A second round of voting

Eur Thyroid J 2021;10:10-38 
Table 1. Consensus statements organized by topics $1-10$

Topic 1: Local control of thyroid hormone action, type 2 deiodinase polymorphisms, and the effects of LT4 monotherapy versus combination therapy

1.1. Future trials of combination therapy in humans should consider including genotyping for the Thr92AlaD2

polymorphism, and should be adequately powered to study the effect of this polymorphism on study outcomes

Topic 2: Nonclassical actions of thyroid hormone

2.1. Consideration should be given to assessment for effects of thyroid hormones that may be manifested through noncanonical as well as canonical pathways (e.g., triglyceride levels and cardiac function) in future trials of combination therapy

2.2. Consideration should be given to assessment for effects of thyroid hormones that may operate by non-thyroid hormone receptor-mediated pathways (e.g., cancer progression) in future trials of combination therapy

Topic 3: Thyroid hormone transporters and CNS levels of thyroid hormone 3.1. A consideration for future trials of combination therapy in humans is that they could be adequately powered to study the effect of polymorphisms in thyroid hormone transporters (e.g., MCT8, MCT10, and OATP1C1) on study outcomes

Topic 4: Selection of participants for combination therapy trials

4.1. After exclusion of other causes of these symptoms, patients who do not report relief of their symptoms with LT4 therapy should specifically be recruited for combination therapy trials

4.2. One or all of several previously validated thyroid-related QoL questionnaires should be used to assess the

baseline dissatisfaction to be used as an inclusion criterion

4.3. Patients should be treated with at least $1.2 \mu \mathrm{g} / \mathrm{kg}$ per day of LT4 to be eligible

4.4. Patients who have low baseline serum total T3 levels while taking LT4 monotherapy should be included in trials, and results could be stratified according to the change in trough total T3 levels achieved with combination therapy

Topic 5: T3/T4 dose equivalence - clinical and trial data

5.1. Future combination therapy trials should incorporate measurement of trough levels of both serum fT4 and total T3 (e.g., as a nested pharmacokinetic study in a representative small subgroup)

5.2. Future combination therapy trials should incorporate measurement of peak levels of serum total T3 $(\sim 1.8-2.5 \mathrm{~h}$ after LT3 administration) as a nested pharmacokinetic study in a representative small subgroup

Topic 6: Target T3 and TSH levels and slow-release T3

6.1. The goal of future LT4/LT3 combination studies should be to achieve a physiological fT3/fT4 ratio

6.2. If nonslow-release LT3 therapy is used, it should be given at least twice daily

6.3. The use of slow-release T3 preparations is desirable in future trials of combination LT4/LT3 therapy to achieve

physiological levels of thyroid function. However, no approved slow-release T3 therapies are available at this time

Topic 7: Psychological and QoL measures

7.1. If a PRO is used as a primary outcome in clinical trials, the measure should have well-documented content and validity for thyroid-related QoL as well as responsiveness to change

7.2. Future studies need to be appropriately powered for PROs as primary outcomes based on the primary endpoint on an effect size of at least 0.5 , and preferably 0.3

7.3. ThyPRO-39 is favored as a primary QoL endpoint for the study

7.4. Patient preference should be included as a secondary trial outcome

100

7.5. A qualitative study should be considered to explain patient preferences for thyroid hormone formulations

Topic 8: Biological outcomes, biomarkers, and safety measures

8.1. Metabolic efficacy outcomes in future trials should include body weight and lipid panel. Resting energy expenditure should be considered for study in a nested subgroup

8.2. Cardiac efficacy outcomes in future trials should include resting heart rate

8.3. Cognition efficacy outcomes should include fluid cognition testing. The NIH Toolbox cognitive battery is a viable option

8.4. Musculoskeletal efficacy outcomes in future trials should include a bone biomarker (e.g., C-telopeptide), and should consider measurement of bone density using DXA scan if the trial is 12 months or longer in duration 8.5. Safety monitoring should incorporate measurement of thyrotoxic symptoms, hypothyroid symptoms, and adverse events 
8.6. Safety monitoring should incorporate cardiac monitoring with ECG at baseline and 3-month intervals. Cardiac

rhythm monitoring of longer duration could be considered in a nested subgroup

8.7. Pilot trials are needed to explore additional outcomes of secondary importance as well as relationships between

variables. Such studies may be conducted within a larger trial

Topic 9: Trial design considerations

9.1. A future combination therapy trial should be randomized, placebo controlled, and double blinded

9.2. A future combination therapy trial should be at least 1 year in duration, with interim outcome assessments at 3 and 6 months

9.3. A future combination therapy trial should incorporate a parallel design

9.4. A future combination therapy trial should consider incorporating an arm being treated with desiccated thyroid extract, in addition to the LT4 and LT4/LT3 arms

9.5. It is important for future trials to be pragmatic and include patients with managed stable comorbidities, so that the results are generalizable to the hypothyroid patient population

Topic 10: Incorporation of patient experiences

10.1. A $2 \times 2$ factorial design randomized controlled trial, randomizing patients to either LT4 or combination therapy and to either a lifestyle intervention (e.g., education, diet, exercise, or a combination) or no lifestyle intervention could be considered to inform the understanding of the effects of pharmacological and nonpharmacological interventions on patient experiences of their therapy

10.2. The level of interaction between patient and physician should be considered as a factor affecting satisfaction with therapy in future trials, and should, therefore, be carefully standardized.

10.3. Fatigue/tiredness measures can be assessed in future trials using the composite scale of ThyPRO 39 or the full Tiredness scale from the 85 -item ThyPRO (see Topic 7 also)

10.4. Neurocognitive testing instruments selected for future trials should be tested to determine whether they are responsive to changes in "brain fog" (see Topic 8 also)

CNS, central nervous system; LT3, liothyronine; LT4, levothyroxine; PRO, patient-reported outcome; T3, triiodothyronine; T4, thyroxine; ThyPRO, Thyroid-specific Patient Reported Outcome; TSH, thyrotropin; QoL, quality of life; ECG, electrocardiogram; DXA, dual-energy X-ray absorptiometry.

was requested for the modified Consensus Statements. A third round of voting was obtained for six Consensus Statements that had undergone modifications after the second review. Further discussion and a fourth round of voting were not pursued to try and obtain a greater degree of consensus. After the third set of modifications, final versions of the article and Consensus Statements were produced and provided to the group for ultimate approval. Input from the two patient representatives involved in the conference and input from patients attending the conference were considered in the topic discussions and summaries, but these stakeholders were not formally members of the writing group.

Conflicts of interest were collected for each of the 12 participants before the presentations on November 3, 2019. Some declared conflicts were deemed to not be relevant to the material being discussed. Five authors had relevant conflicts and their input was not solicited for the applicable material within the document and Summary Statements, and their vote was not ascertained for the Consensus Statement drawn from this topic material (such votes were marked as abstentions).

The exclusions were as follows: A.C.B.: Topic 6: Target T3 and TSH levels and Slow-Release T3 (section 6.3) and Topic 9: Trial Design Considerations (section 9.4 on therapies to be studied),
F.S.C.: Topic 9: Trial Design Considerations (section 9.4 on therapies to be studied), T.W.: Topic 7: Psychological and Quality of Life Measures (section 7.1, 7.2, 7.3), Topic 9: Trial Design Considerations (section 9.4 on therapies to be studied), and Topic 10: Incorporation of Patient Experiences (section 10.3), E.F.: Topic 9: Trial Design Considerations (all sections), B.N.: Topic 9: Trial Design Considerations (all sections). Eighteen abstentions for the 408 votes on all 34 Consensus Statements were recorded in total.

Approval for the joint conference was provided in advance by the relevant committees and leadership of the ATA, BTA, and ETA according to society policies. The concept for this Consensus Document was approved by the ATA Board of Directors, and the ATA Guidelines and Statements Committee, who also reviewed and approved the conflict of interest management plan. The near-final article was approved by the relevant committees of the ATA, BTA, and ETA and also made available for comments from the membership of all three societies for a comment period of 30 days. Although the relevant literature was extensively reviewed, no formal systematic review or grading of evidence was undertaken. The consensus statements were compiled based on expert opinion and are not graded recommendations. 


\section{Results: Topics Summaries, Summary Statements, and Consensus Statements}

Consensus Statements encapsulating the implication of the material with respect to the design of future clinical trials were generated. After mutually agreed upon modifications, 34 Consensus Statements were available for voting. There were 28 Consensus Statements upon which there was consensus from at least $75 \%$ of the group ( 9 out of 12 individuals), with lesser degrees of consensus regarding the remaining 6 Consensus Statements. Thus, a consensus among at least $75 \%$ of authors was achieved for the majority of Consensus Statements. The Consensus Statements with at least $75 \%$ agreement are presented in this document as important considerations for the design of future clinical trials of combination therapy (Table 1). Out of those 28 statements with at least $75 \%$ agreement, there were 13 statements for which $100 \%$ consensus was achieved. The Consensus Statements with $<75 \%$ agreement are in italics and could be considered if future studies provide additional rationale.

Topic 1: Local Control of TH Action, Type 2

Deiodinase Polymorphisms, and the Effects of LT4

Monotherapy versus Combination Therapy (Presenter at Live Conference: A.C.B., Topic Summarizer: J.J.)

\section{Local Control of TH Action: The Consequence of}

Monotherapy versus Combination Therapy

The Consequence of Monotherapy versus

Combination Therapy in Rodent Models

The rationale for treatment with LT4 is that two deiodinase pathways, the type 1 deiodinase (D1) and the type 2 deiodinase (D2), convert thyroxine (T4) to triiodothyronine (T3), restoring the pool of T3 and clinical euthyroidism. Seminal studies from the Escobar-Morreale group first showed that LT4 therapy given to hypothyroid rats did not achieve normal serum T3 levels, nor did it result in normal T3 levels in all tissues sampled [2]. They also showed restoration of normal tissue levels of THs with combination therapy with both LT4 and LT3 in rats [3]. Later studies in LT4-treated rats discovered that the hypothalamus [4] and thyrotroph cell lines [5] convert T4 to T3 more efficiently than other tissues due to relatively less T4-induced inactivation of D2 through ubiquitination.

Figure 1 illustrates the relative roles of the D1 and D2 pathways in the thyrotropin (TSH) feedback mechanism during treatment with LT4 [4-8]. Thus in rodent models, TSH secretion is normalized before T3 levels are fully restored in the plasma and other tissues, resulting in low circulating T3 levels and "tissue hypothyroidism." Use of combination therapy with both LT4 and LT3 in hypothyroid rats also normalized serum TSH but additionally allowed the T3 deficit in peripheral tissues to be redressed [4]. In keeping with this, markers of euthyroidism, such as serum cholesterol levels, mitochondrial content, and enzymatic activity within liver and skeletal muscle, better approximated values in control rats when sustained delivery of both LT4 and LT3 was employed. Likewise, the pattern of T3-responsive genes in the brain was more similar to that of control rats when combination therapy was employed [4].

The Consequence of Monotherapy versus

Combination Therapy in Humans

It has been well established that there are two changes in TH levels that occur in patients being treated for hypothyroidism with LT4 monotherapy. These changes are an increase in T4 or free T4 (fT4) levels, an increase in fT4/ $\mathrm{T} 3$ ratios, associated with a decline in $\mathrm{T} 3$ or free T3 (fT3) levels. Depending on the study, mean serum T3 or fT3 levels may be in the lower half of the normal range, and levels may even be below the normal range in up to $15 \%$ of athyreotic individuals [9-12]. These differences all occur despite comparable serum TSH levels. In fact, in a cross-sectional study based on the US National Health and Nutrition Examination Survey data base, serum T3 and fT3 levels were 10\% lower in LT4-treated patients than in a control group matched for sex, age, ethnic background, and TSH levels [13]. While LT4 therapy is very effective in normalizing serum TSH levels, it fails to restore euthyroidism in some tissues based on an array of metabolic parameters such as serum cholesterol levels and other biomarkers that remain abnormal in LT4treated patients, despite a normal serum TSH [14-16].

In the 14 trials of combination therapy for hypothyroidism in humans (Table 2), the TSH levels and T3 levels achieved during LT4/LT3 combination therapy were varied, with not all studies maintaining comparable TSH levels during combination therapy as were seen with LT4 monotherapy, or even achieving higher T3 levels during combination therapy (although this could be a consequence of the timing of blood sampling; online suppl. Table 1; see www. karger.com/doi/10.1159/000512970 for all online suppl. material) [9]. As would be expected based on a lowering of the LT4 dose, fT4 levels were universally lower with combination therapy. However, $\mathrm{fT} 4 / \mathrm{T} 3$ ratios achieved in combi-
Jonklaas et al. 


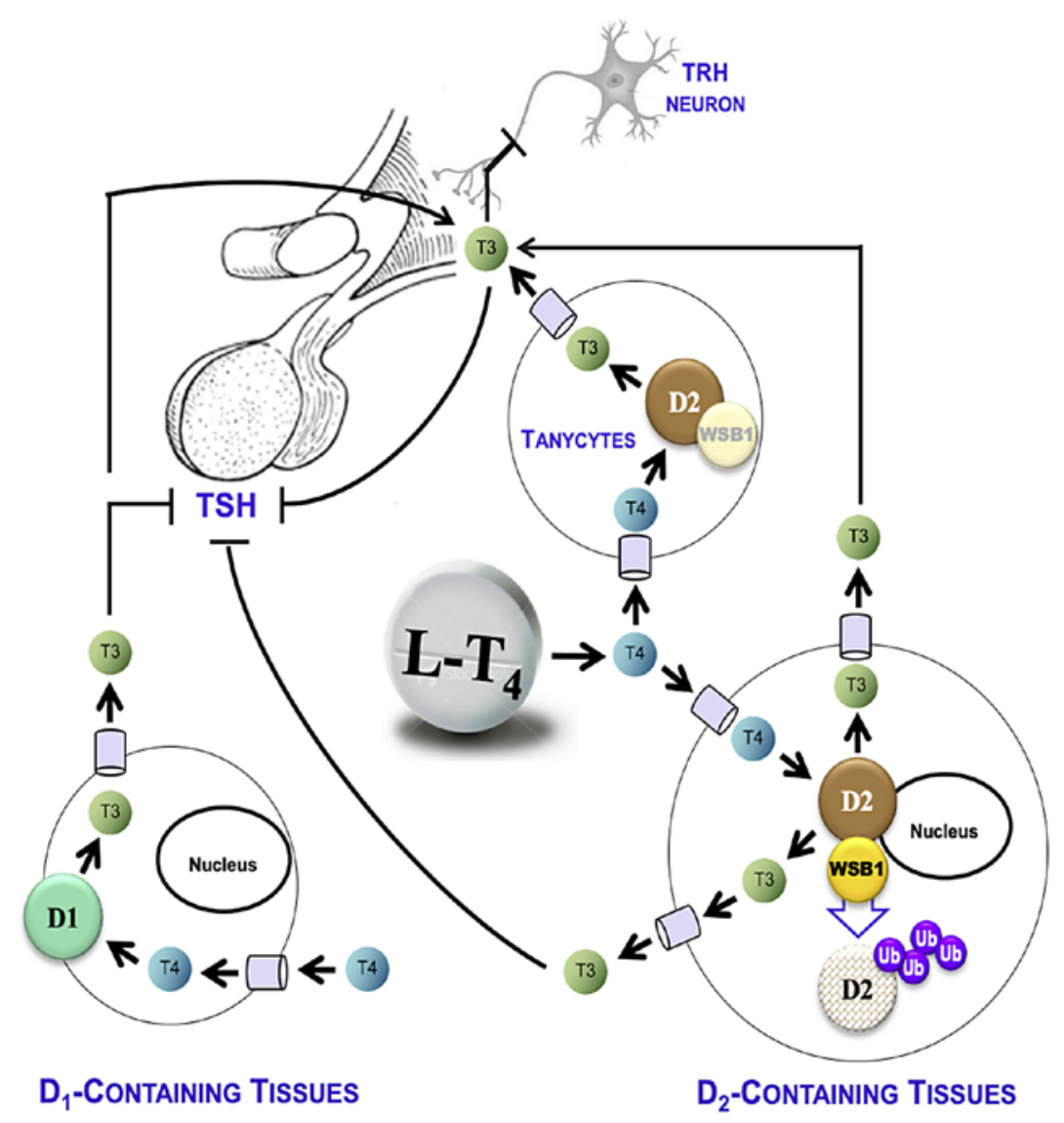

Fig. 1. Relative roles of the D1 and D2 pathways in the TSH feedback mechanism during treatment with LT4. In LT4-treated thyroidectomized patients to achieve normal serum TSH levels, the D2 pathway contributes with $\sim 80 \%$ of the circulating T3 [6]. Studies performed in rats revealed how plasma T4 is taken up by the hypothalamic tanycytes and the pituitary thyrotrophs, and locally converted to T3 through the D2 pathway [8]. The net effect of the $\mathrm{D} 2$ activity in these two sites is a reduction in TSH secretion. As the goal of therapy with LT4 is to normalize serum TSH, a progressive increase in LT4 dose increases circulating T3 levels (predominantly through D2) and simultaneously reduces TSH secretion (predominantly through D2). Studies performed in rodents demonstrated that the $\mathrm{D} 2$ pathway is negatively regulated by $\mathrm{T} 4$, that is, D2 is ubiquitinated by WSB-1 and inactivated as it converts T4 to T3 [7]. However, this process occurs at a much slower rate in

nation therapy do not replicate the native euthyroid state that is characterized by higher $\mathrm{fT} 4 / \mathrm{T} 3$ ratios than those seen with combination therapy $[10,17]$. Assessment of objective $\mathrm{TH}$-dependent metabolic effects varied among these trials, which focused primarily on cognition, mood, and quality of life (QoL; online suppl. Table 2).

Combination Therapy Consensus

Statement the hypothalamus [4]. Also in pituitary thyrotrophs, the loss of D2 activity caused by T4 is a much slower process [5]. As a result, D2mediated $\mathrm{T} 3$ production is a more efficient process in the hypothalamus/pituitary unit when compared with other D2-containing tissues. Thus, while increasing the LT4 replacement dose to treat hypothyroidism, normalization of serum TSH levels will occur before full normalization of serum T3 levels. The role played by D1 is secondary, mainly because its affinity for T4 is three orders of magnitude less than D2, and its expression is positively regulated by plasma T3. Thus, D1 activity was never fully normalized in LT4treated hypothyroid rats, only when a combination of LT4 and LT3 was used was serum T3 restored [4]. D1, type 1 deiodinase; D2, type 2 deiodinase; LT4, levothyroxine; T3, triiodothyronine; T4, thyroxine; TSH, thyrotropin; WSB-1, gene encoding the WD repeat and SOCS box-containing protein 1.

\section{D2 Polymorphisms, and the Effects of LT4 Monotherapy versus Combination Therapy}

The Impact of D2 Polymorphisms in Mice

Since the first description of the Thr92Ala polymorphism of the type 2 deiodinase gene (DIO2; Thr92Ala- 
Table 2. Characteristics of clinical trials of synthetic combination therapy

\begin{tabular}{|c|c|c|c|c|c|c|c|c|}
\hline Authors & Year & $\begin{array}{l}\text { Participants, } n \\
\text { (total } n=1,257 \text { ) }\end{array}$ & $\begin{array}{l}\text { Mean age, } \\
\text { years }\end{array}$ & Sex, \% F & Dose LT3 & $\begin{array}{l}\text { Dosing } \\
\text { frequency }\end{array}$ & $\begin{array}{l}\text { Approximate } \mu \mathrm{g} \\
\text { ratio of } \mathrm{T} 4: \mathrm{T} 3\end{array}$ & Duration \\
\hline Appelhof [53] & 2005 & 130 & $46-49$ & $83-89$ & LT4/LT3 $10: 1$ or $5: 1$ & Twice daily & $10: 1$ or $5: 1$ & 15 weeks \\
\hline Bunevicius [46] & 1999 & 33 & 46 & 94 & $\begin{array}{l}\text { LT4 }-50 \mu \mathrm{g} / \text { day, } \\
\text { LT3 }+12.5 \mu \mathrm{g} / \text { day }\end{array}$ & Once daily & $10: 1$ & 5 weeks \\
\hline Bunevicius [51] & 2002 & 10 & 34 & 100 & $\begin{array}{l}\text { LT4 }-50 \mu \mathrm{g} / \text { day, } \\
\text { LT3 }+10.0 \mu \mathrm{g} / \text { day }\end{array}$ & Once daily & $6.5: 1$ & 5 weeks \\
\hline Clyde [17] & 2003 & 44 & $43-45$ & $77-86$ & $\begin{array}{l}\text { LT4 }-50 \mu \mathrm{g} / \text { day, } \\
\mathrm{LT} 3+15.0 \mu \mathrm{g} / \text { day }\end{array}$ & Twice daily & $6.5: 1$ & 4 months \\
\hline $\begin{array}{l}\text { Escobar-Mor- } \\
\text { reale [49] }\end{array}$ & 2005 & 26 & 48 & 100 & $\begin{array}{l}\text { LT4 } 75 \mu \mathrm{g} / \text { day, } \\
\text { LT3 }+5 \mu \mathrm{g} / \text { day }\end{array}$ & Once daily & $15: 1$ or $12: 1$ & 8 weeks \\
\hline Fadeyev [78] & 2010 & 36 & $40-43$ & 100 & $\begin{array}{l}\text { LT4 }-25 \mu \mathrm{g} / \text { day, } \\
\text { LT3 }+12.5 \mu \mathrm{g} / \text { day }\end{array}$ & Once daily & $6: 1$ & 6 months \\
\hline Rodriguez [59] & 2005 & 27 & 47 & 83 & $\begin{array}{l}\text { LT4 }-50 \mu \mathrm{g} / \text { day, } \\
\text { LT3 }+10.0 \mu \mathrm{g} / \text { day }\end{array}$ & Once daily & $7: 1$ & 6 weeks \\
\hline Saravanan [47] & 2005 & 573 & 57 & $83-84$ & $\begin{array}{l}\text { LT4 }-50 \mu \mathrm{g} / \text { day, } \\
\text { LT3 }+10.0 \mu \mathrm{g} / \text { day }\end{array}$ & Once daily & $8: 1$ & 12 months \\
\hline Sawka [60] & 2003 & 33 & 49 & 90 & $\begin{array}{l}\text { LT4 }-50 \mu \mathrm{g} / \text { day, } \\
\mathrm{LT} 3+25.0 \mu \mathrm{g} / \text { day }\end{array}$ & Twice daily & $3.5: 1$ & 15 weeks \\
\hline Siegmund [71] & 2004 & 23 & $23-69$ & 81 & $\begin{array}{l}\text { LT4 }-5 \%+ \\
\text { LT3 5\% aim 14:1 ratio }\end{array}$ & Once daily & $19: 1$ & 12 weeks \\
\hline
\end{tabular}

Italics indicates desiccated thyroid extract. Reprinted with adaptations with permission from Taylor \& Francis Ltd. from Jonklaas [104].

DIO2) in humans as a gene variant associated with increased body mass index and insulin resistance [18], Thr92Ala-DIO2 has also been found to be important for $\mathrm{TH}$ action. Studies in cells show profound effects of polymorphisms in the DIO2 on the action of TH. Transfection studies in cultures of mouse pituitary cells from DIO2-null mice resulted in less TSH suppression in cells expressing the DIO2 Ala/Ala homozygote, as compared with cells expressing wild type Thr92-DIO2 [19]. Furthermore, HEK-293 cells stably expressing Thr92AlaDIO2 produced $\sim 20 \%$ less T3 over time than cells expressing Thr92-DIO2 [20].
Studies comparing human and rodents should bear in mind interspecies differences. On one hand, the rodent thyroid produces relatively more T3 than the human thyroid, theoretically placing LT4-treated hypothyroid mice at a higher risk of developing low serum T3 levels. On the other hand, the D2 pathway has a much greater role in humans than in rodents, placing humans at a higher risk of exhibiting low tissue and serum T3 levels due to a D2 defect. Nonetheless, despite these differences in TH economy, it is notable that in both rodents and humans, treatment with LT4 monotherapy normalizes serum TSH while serum T3 is either in the lower part of the normal range or below the normal range.
16 
Although intact mice homozygous for the Thr92Ala polymorphism had normal serum T3 levels, they did not engage in as much physical activity, slept more, and required more time to memorize objects than their wild type counterparts [21]. Studies on T3-responsive genes within different brain areas indicate that $\mathrm{T} 3$ actions in the brains of Thr92Ala-DIO2 mice are reduced, perhaps pointing to localized "hypothyroidism." The previously mentioned alterations in activity, sleep, and cognition were intensified when the homozygous mice were rendered hypothyroid by adding methimazole to their drinking water. Moreover, these deficits were better redressed in these hypothyroid mice when they received treatment with combination therapy as compared with treatment using monotherapy with LT4 [21]. These studies shed light on the reduced catalytic activity of the Thr92Ala-D2 enzyme and suggest that $\mathrm{TH}$ action in tissues that rely on D2-generated T3 (e.g., brain) is at risk during treatment with LT4. This conclusion is applicable to both small rodents and humans. Thus, while advancements have been made toward understanding the impact of the Thr92Ala$\mathrm{DIO} 2$ in the rodent model, further investigations of human carriers of this polymorphism are needed before major conclusions and recommendations could be formulated for hypothyroid patients.

\section{Preliminary Data Regarding D2 Polymorphism in}

Humans

Human genetic association studies of single nucleotide polymorphisms (SNPs) explain only a limited proportion of phenotypic variation among individuals. This could reflect interference from structural and epigenetic variants, alleles with additive effects, or synergistic interactions. Therefore, not surprisingly, data obtained in different populations across the world regarding the significance of the Thr92Ala-DIO2 polymorphism with respect to the treatment of hypothyroidism in humans are preliminary and conflicting. A post hoc analysis in the UK showed that although this polymorphism had no impact on serum TH levels, it did predict the response to the therapy chosen for hypothyroidism [22]. Those that were homozygous for the polymorphism had less psychological well-being (as measured by the General Health Questionnaire [GHQ] 12) while taking LT4, and more improvement when combination therapy was used, compared with participants carrying the wild type allele. Using stored samples from one of the combination therapy trials from 2009 [23], a 2017 analysis showed that patients with either the monocarboxylate transporter (MCT)10 polymorphism or both the MCT10 and
Thr92Ala polymorphism preferred combination therapy ( $p$ values 0.018 and 0.009 , respectively) [24]. However, a more recent study in the Netherlands did not find any impact of Th92Ala-DIO2 genotype on the response to LT4 monotherapy in terms of health-related QoL or cognitive function or an effect in the general population [25]. Notably, an Italian study with a relatively small number of participants revealed that LT4-treated thyroidectomized carriers of at least one Thr92Ala-DIO2 allele exhibited lower serum T3 levels, despite a normal serum TSH [19]. If replicated, these data could indicate that alterations in DIO2 may, in fact, affect circulating T3 levels in those who are athyreotic and treated with LT4.

Summary statements

- In vitro, increasing T4 levels inhibits D2 activity except in cell lines derived from the pituitary, suggesting that a high fT4/fT3 ratio may lead to a "normal" TSH while reducing $\mathrm{T} 3$ generation in peripheral tissues.

- In hypothalamic extracts, D2 inactivation is a much less efficient process as compared with other tissues. This would reinforce a predominant role of T4 and localized T3 production in the hypothalamus-pituitary unit to mediate the TSH feedback mechanism.

- Hypothyroid rats treated with LT4 to restore serum TSH have lower T3 levels in the serum and in some tissues than control rats, but $\mathrm{T} 3 \mathrm{l}$ levels are restored with combination therapy that adds LT3.

- Tissue markers of TH action (serum cholesterol, T3responsive genes) in LT4-treated thyroidectomized rats with normal serum TSH indicate residual hypothyroidism; no differences compared with control rats were observed in the thyroidectomized rats treated with LT4/LT3.

- Mice homozygous for the Thr92Ala-DIO2 polymorphism have a hypothyroid-like pattern of T3-responsive genes in certain areas of the central nervous system (CNS) when compared with wild type mice.

- Mice homozygous for the Thr92Ala-DIO2 polymorphism engage in less physical activity, sleep more, and have shortterm memory problems when compared with wild type mice.

- Physical activity, sleep patterns, and short-term memory in hypothyroid Thr92Ala-DIO2 homozygous mice improve more with LT4/LT3 than with LT4 therapy alone.

- The impact of the Thr92Ala-DIO2 polymorphism on the clinical treatment benefit of combination therapy for hypothyroidism in humans is currently unclear. 


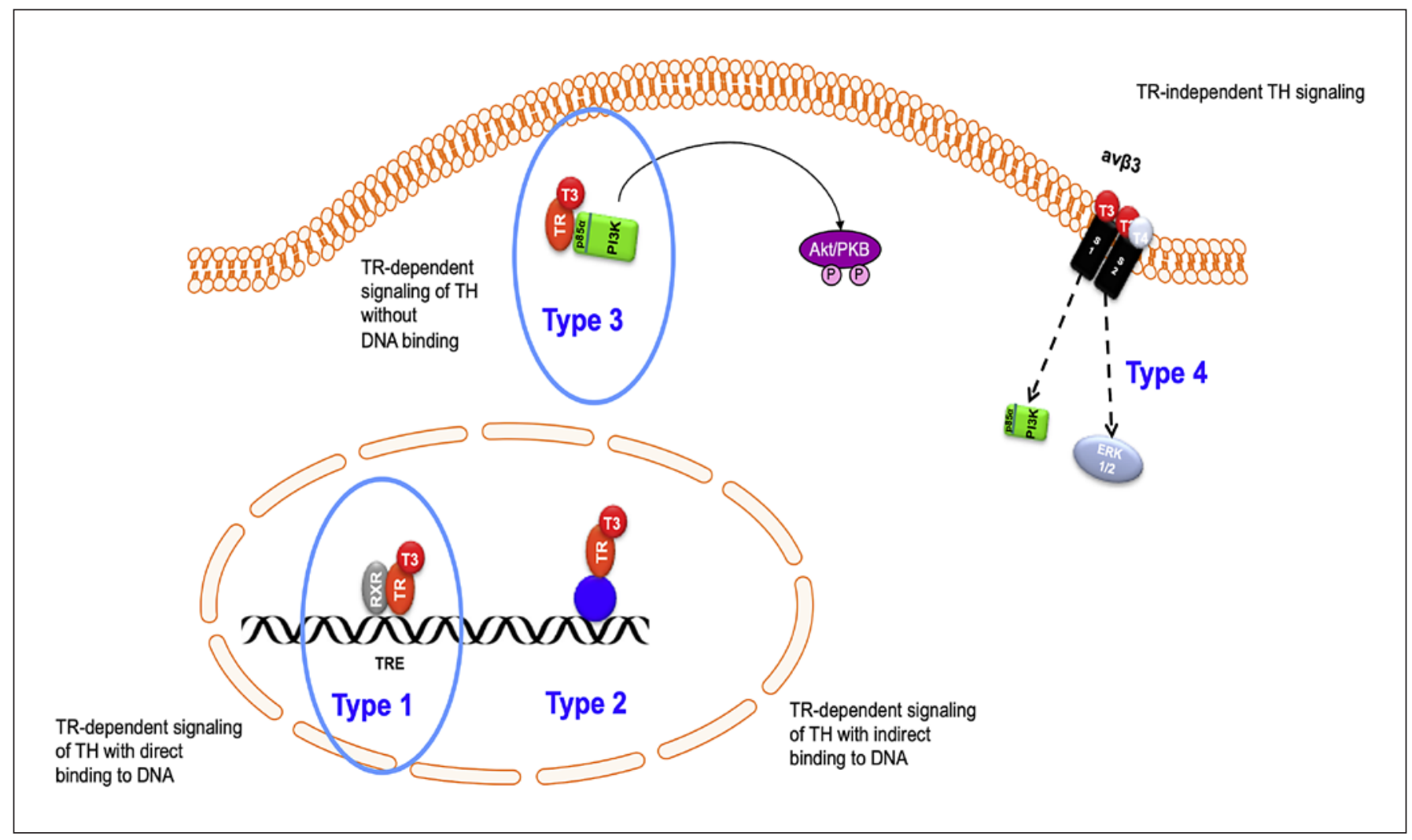

Fig. 2. Depiction of the four types of thyroid hormone signaling.

Topic 2: Noncanonical Actions of TH (Presenter at Live Conference: L.C.M., Topic Summarizer: C.M.D.)

\section{Different Pathways of TH Action}

$\mathrm{TH}$, in the form of $\mathrm{T} 3$, has classically been considered to act by binding to cytosolic TH receptors (TR) (TRa1, $\mathrm{TR} \beta 1$, and TR $\beta 2$ ) that bind to $\mathrm{TH}$ response elements on the DNA and regulate expression of TH target genes (canonical TH/TR action) [26, 27]. However, there is now evidence of additional noncanonical mechanisms of TH action, and four types of TH signaling have recently been defined: Type 1 (canonical) $=$ TR-dependent signaling of TH with direct binding to DNA; Type 2 = TR-dependent signaling of TH with indirect binding to DNA; Type $3=$ TR-dependent signaling of TH without DNA binding, for example, through PI3K; Type $4=$ TR-independent TH signaling, for example, through integrin $\alpha v \beta 3$ (Fig. 2) [28].
Different Clinical Effects May Occur through Different Pathways

The comparison of wild type mice with mice in which the TR $\alpha$ or TR $\beta$ gene has been knocked out and mice in which the TRs are still present, but can no longer bind to DNA (TRa GS and TR $\beta$ GS mice), allows attribution of $\mathrm{TH}$ effects to the relevant signaling pathway [29]. Online supplementary Table 3 summarizes the findings. Canonical signaling predominates (at least in mice) for hypothalamic pituitary thyroid (HPT) feedback, hearing, bone development, growth, and browning of adipose tissue. However, cardiac hypertrophy, vasodilation, and triglyceride synthesis are mediated by noncanonical cytosolic signaling (Type 3). In addition, T4 stimulates growth of cancer cells and tumors independently of either TRa or $\operatorname{TR} \beta$ through $\alpha v \beta 3$, the type 4 noncanonical pathway (online suppl. Table 3) [30-32].

In humans, hypothyroidism is associated with a poor prognosis in established heart failure [33] and TH can reduce intrahepatic triglyceride content [34, 35]. Thyroid dysfunction, mostly hypothyroidism, is an adverse effect
Jonklaas et al. 


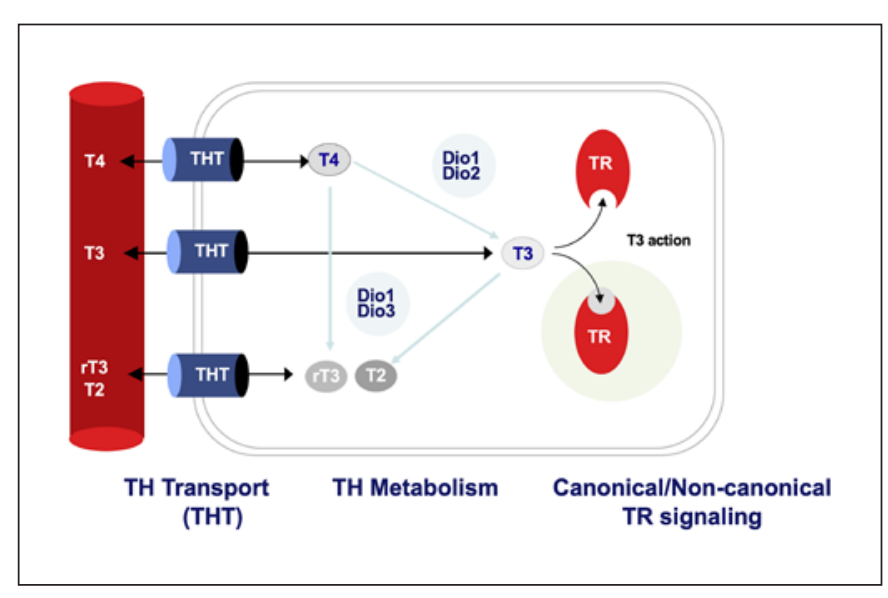

Fig. 3. Transporters allowing thyroid hormone entry into cells.

of checkpoint inhibitor treatment for cancer, and has been associated with longer survival in these studies [36, 37]. Whether the occurrence of adverse effects merely indicates efficacy of the treatment or whether hypothyroidism indeed has a beneficial effect on limiting tumor progression, possibly mediated through reduced T4 action through $\alpha v \beta 3$, has yet to be determined.

\section{Relevance to Studies of TH Replacement}

The effects of differences in T4:T3 ratio on $\mathrm{TH}$ action through noncanonical or canonical pathways are unknown, but it is noted that HPT axis feedback (i.e., TSH levels) is likely to be only reflective of canonical TR $\beta$ signaling. Experimental data on stimulation of tumor growth by $\mathrm{T} 4$ indicate that cancer progress could be influenced by $\mathrm{TH}$, possibly more by $\mathrm{T} 4$ than by $\mathrm{T} 3$. Although hypothyroidism is an adverse effect of cancer therapy (e.g., tyrosine kinase or checkpoint inhibitors), the influence of $\mathrm{TH}$ substitution with either T4 alone or T3/T4 combination on cancer growth has not yet been determined.

It is also noted that in users of T3 in an epidemiology study comparing $\mathrm{T} 3$ with $\mathrm{T} 4$ users, there was a trend toward an increased risk of breast cancer in the T3 users [38]. However, the literature on breast cancer risk relative to thyroid disease or TH levels is complex. Both thyroid disease and breast cancer are relatively common in women, so inferring any relationship has far-reaching implications, unless based on well-substantiated consistent evidence [39, 40]. Evaluation of the effects of THs that may manifest through noncanonical and canonical pathways is needed in basic science/translational research and in future clinical trials.
Summary statements

- THs have effects that are exerted through TRs but through noncanonical pathways, such as effects on triglyceride levels and some cardiovascular functions.

- THs may also exert effects that occur through non-TRmediated pathways, such as modification of cancer growth.

- More research is needed examining the effects of THs that may operate by noncanonical and non-TR-mediated pathways (e.g., cancer progression).

Topic 3: TH Transporters and CNS Levels of TH (Presenter at Live Conference: H.H., Topic Summarizer: C.M.D.)

\section{Access of TH into the Brain and the TH Transporter Family}

TH transporters facilitate the transmembrane passage of $\mathrm{TH}$ and its metabolites and are thus mandatory for proper TH metabolism and action in every tissue (Fig. 3) [41, 42]. In the CNS, $\mathrm{TH}$ transporter activities are not only required in prominent TH target cells (such as neurons, oligodendrocytes, and astrocytes) but also in all cell types of the brain barriers (such endothelial cells, astrocytes epithelial cells, and ependymal cells) to allow $\mathrm{TH}$ entry into the brain (Fig. 4). Consequently, absence of critical TH transporters can greatly interfere with proper TH signaling in the CNS and may also affect the activity of the HPT axis.

\section{TH Transporters, Thyroid Function, and CNS Effects}

Interference with proper signaling is best illustrated in patients with Allan-Herndon Dudley syndrome [41]. These patients carry inactivating mutations in the $\mathrm{TH}$ transporting MCT8 encoded by the X-linked SLC16A2 gene. Affected patients exhibit a severe form of psychomotor retardation in combination with an abnormal thyroid function profile (elevated $\mathrm{T} 3$, reduced $\mathrm{T} 4$ in the presence of normal-elevated TSH). While several clinical parameters such as low body weight, muscle wasting, tachycardia, and increased sex hormone binding globulin are indicative of a hyperthyroid situation in peripheral tissues, histopathological observations (including hypomyelination, compromised GABAergic maturation in cerebral and cerebellar cortex), as well as reduced $\mathrm{TH}$ tissue brain content point to an overall $\mathrm{TH}$-deficient situation inside the CNS $[42,43]$. Mouse studies have revealed a critical function not only of MCT8 but also the T4 transporting organic anion transporting protein (OATP) 
Fig. 4. Transporters allowing thyroid hormone entry into the brain. Adapted with permission from Groeneweg et al. [41].

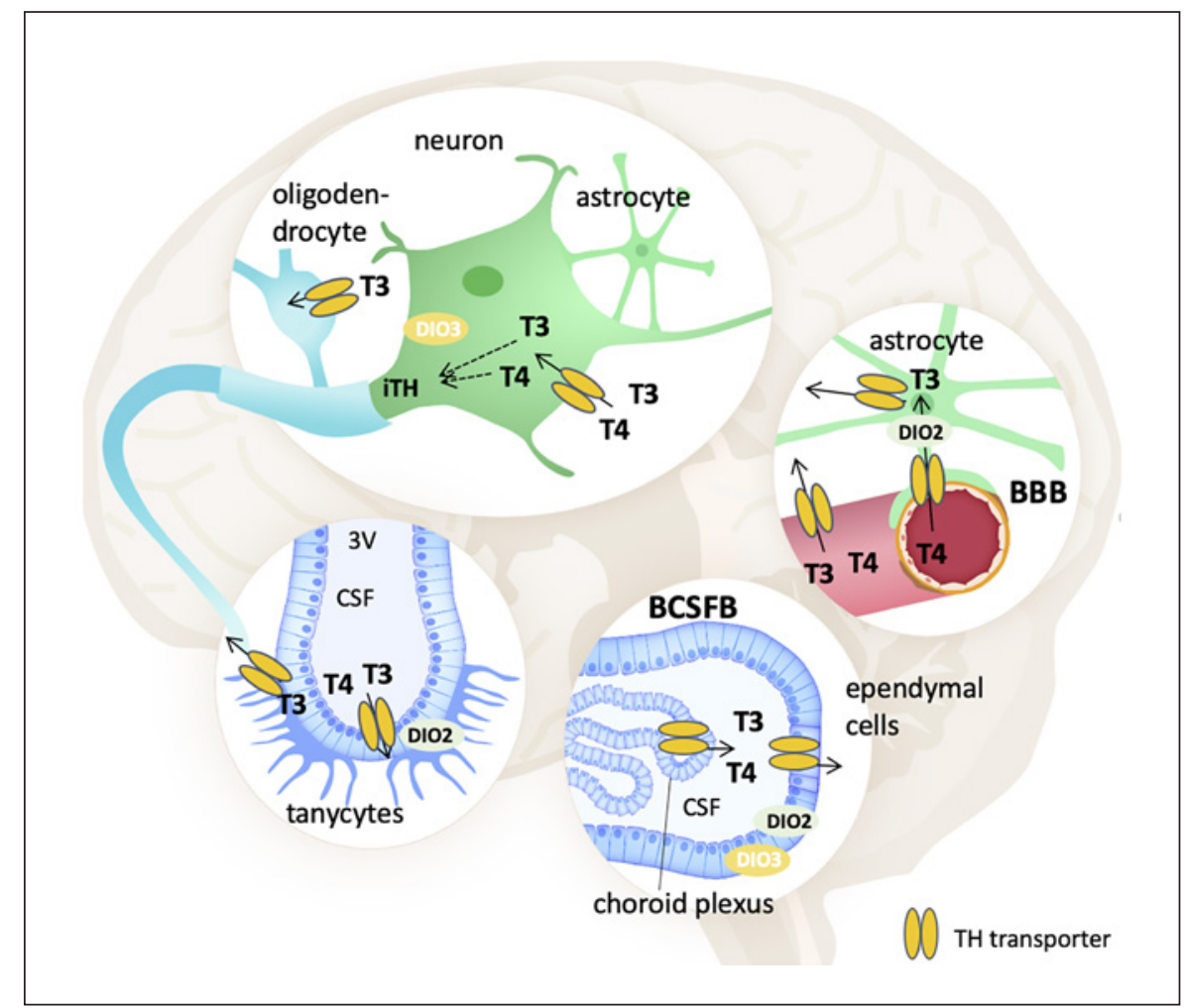

OATP1C1 (encoded by the SLCO1C1 gene) in facilitating $\mathrm{TH}$ passage across brain barriers. Murine studies also provide strong evidence that apart from MCT8 and OAT$\mathrm{P} 1 \mathrm{C} 1$, additional $\mathrm{TH}$ transporters yet to be defined in humans must be active to ensure proper neural activity and a functional HPT axis [41].

\section{The Role of Common Variations in TH Transporter Genes}

While rare mutations in $\mathrm{TH}$ transporter genes can clearly cause disturbed brain TH metabolism and action, the physiological relevance of more common variations in TH transporter genes is still largely unknown. Common SNPs in MCT8, TH transporting MCT10, and THtransporting OATPs have been reported to have little impact on serum TH parameters [44]. However, their impact is more likely to be on intra- rather than on extracellular levels, and polymorphisms in OATP1C1 gene have been associated with fatigue and depression in hypothyroid patients [45]. Further investigations should address the influence of common genetic variations in $\mathrm{TH}$ transporter genes on proper $\mathrm{TH}$ brain function, as circulating TH concentrations do not necessarily reflect the cellular TH status within the CNS.
Summary statements

- Alterations in TH transporter expression in the CNS and/or pituitary may compromise proper feedback within the HPT axis and polymorphisms may affect thyroid function tests on LT4/LT3 replacement.

- Alterations in TH transporter expression in the CNS may affect brain function and polymorphisms may affect the neural response to LT4/LT3 replacement.

Topic 4: Participant Eligibility Considerations for Combination Therapy Trials (Presenters at Live Conference: Several, Topic Summarizer: J.J.)

Randomized Controlled Trial Results in the Published Literature without Specific Selection for Symptomatic or Dissatisfied Patients

As previously summarized in the ATA clinical practice guidelines on TH replacement, 14 trials of combination therapy with LT4/LT3 have been conducted (Table 2; online suppl. Table 1-2) [9]. Most of these trials did not support superiority of LT4/LT3 combination therapy over LT4 alone. However, a few trials showed overall benefits 
in terms of mood, QoL, and neurocognitive function, and a few additional trials showed some benefits in some measures that were assessed. With respect to QoL or mood, superiority of combination therapy on multiple measures was seen in two trials contributing 92 participants [23, 46], superiority on a minority of measures at certain time points was seen in two trials contributing 633 participants $[47,48]$, whereas the remaining nine trials showed no benefit. When considering neurocognitive function, one trial of 33 patients showed benefit on multiple measures [46], one trial of 26 participants showed benefit on a minority of measures [49], and eight trials showed no benefit. There were some issues with these trials in terms of their small size, short duration, use of multiple comparisons, and once-daily dosing regimens. In addition, trial heterogeneity with respect to the dosing regimens, $\mathrm{TH}$ levels, and outcome measures (including lack of validated evaluation of patient preferences [see patient preference section of Topic 7]) has made it difficult to compare results between studies or aggregate these trials in metaanalyses [9]. However, another important consideration with respect to these trials of synthetic combination therapy is whether the appropriate patients were selected for inclusion.

Patient preference was an outcome examined in some of the trials. In the available crossover trials, when examining the patients who completed the trials, four trials that incorporated 128 patients showed there was a preference for combination therapy $[23,46,50,51]$, whereas patients from another trial incorporating 101 patients had no treatment preference [52]. For the parallel design trials, there was a preference for combination therapy in one trial of 130 patients [53], whereas patients from another trial of 697 patients [611 with follow-up data; 573 still on study medication] had no treatment preference [47]. In terms of patient preference based on a recent systematic review and meta-analysis, although there was patient preference for combination therapy in some studies, overall the preference did not differ from that expected by chance when patients preferring LT4 monotherapy and patients having no preference were grouped together [54]. An earlier meta-analysis of the crossover studies suggested that $27 \%$ of patients preferred monotherapy, $25 \%$ had no preference, and $48 \%$ preferred combination therapy [55]. Subjective outcomes such as patient preference are likely to be influenced by the quality of blinding and ability to maintain euthyroidism in study participants. In trials in which some participants had iatrogenic hyperthyroidism, this could either drive patient lack of preference or patient preference for combination therapy. For example, in one

Combination Therapy Consensus

Statement study of iatrogenic hyperthyroidism induced by LT4 therapy, patients had impaired scores on physical health subscales, but improved scores of mental health and mood, perhaps contributing to heterogeneity in patient preferences [56]. Vital signs were not different between treatment groups in one substudy in which $24 \mathrm{~h}$ pulse and blood pressure levels during monotherapy and combination therapy were specifically monitored, suggesting that treatment-related unblinding due to cardiovascular effects is unlikely on low dose combination therapy [57].

One other randomized crossover trial of combination therapy using desiccated thyroid extract (DTE) has also been conducted in 70 patients who were also crossed over to LT4 monotherapy [58], with both preparations delivered in capsules. The primary outcome of this trial was multiple mood and neuropsychological measures, which did not differ between the period during which the patients were taking DTE and the period during which they were taking LT4. However, there was a small but significant weight loss during the 16 -week period that patients were taking the DTE. There was a patient preference for the extract that was associated with the weight loss, but this was only noted in a post hoc analysis.

With respect to the issue of patient preference, although current data show that patient preference is not different from that expected by chance [54], the trials conducted thus far did not specifically seek out patients who were dissatisfied while taking their usual therapy. These trials recruited hypothyroid patients regardless of whether they were symptomatic or not. This could potentially lead to a dilution of patient preference that might have reached statistical significance if only patients dissatisfied with their therapy were recruited. It is also possible that if there is failure to show mood or cognitive benefits in patients who nevertheless prefer combination therapy, this could be due to our lack of knowledge about what is causing the preference and an associated lack of knowledge about how to measure this factor.

\section{Rationale for Selecting Patients Dissatisfied with LT4} Monotherapy or Those with Persistent Hypothyroid Symptoms while Taking LT4 Monotherapy

Prior studies of combination therapy for hypothyroidism have not specifically selected patients who have voiced their dissatisfaction with traditional monotherapy. Some trials have excluded specific patient groups, such as those with mental illness, affective disorders, or untreated depression $[48,49,52]$. One trial prescreened patients for fatigue, stratified them according to their fatigue levels, and ensured equal patient sampling from 
among the low- and high-fatigue level groups [59]. Another trial was conducted in those with depressive symptoms [60]. To attempt to study participants who may be more likely to benefit from combination therapy, several inclusion criteria could be utilized. We believe that with respect to future clinical trials, first and foremost, patients with persistent hypothyroid symptoms or inadequate improvement of their hypothyroid symptoms with LT4 therapy should specifically be recruited, once other causes for these symptoms have been excluded. This is congruent with one of the research priorities identified by the National Institute for Health and Care Excellence in their examination of evidence for the management of hypothyroidism guideline [61]. They stated: "Therefore, there is an urgent need for high quality RCT examining the efficacy and cost-effectiveness of T4-T3 combination treatment in people with hypothyroidism who are not responding to levothyroxine monotherapy."

To quantify dissatisfaction, one of several thyroid-related QoL questionnaires, which have been previously validated in hypothyroid populations, could be employed. These include the hypothyroid-related QoL [62], the Thyroid Symptoms Questionnaire (TSQ) [63], and the Thyroid-specific Patient Reported Outcome (ThyPRO) measure [64]. For example, a score $>4$ in the 12-question TSQ, a validated instrument used to assess hypothyroid symptomatology, could be used as the threshold to define dissatisfaction with the current therapy [65]. Potentially, an overall health-related QoL score using the ThyPRO-39 composite score of, for example, $>32$ could be used for inclusion (see also Topic 7). The score of 32 represents a score sufficiently above a previously found mean among patients with hypothyroidism that these individuals would be expected to have worse QoL than average [66]. Candidate measures of patient-reported outcomes (PROs) should include the complaint that is most important to the patient (e.g., fatigue, weight gain, and brain fog - also described as mental cloudiness or lack of mental alertness).

\section{Other Criteria for Combination Therapy Trial Eligibility}

There are several other considerations with regard to participant eligibility in trials. For example, patients with little residual thyroid function should be recruited, as those individuals who have substantial endogenous thyroid function may be less affected by manipulation of their exogenous therapy [67]. As a measure of having litthe endogenous function, patients could be required to be treated at baseline with at least $1.2 \mu \mathrm{g} / \mathrm{kg}$ per day of LT4 while achieving a normal serum TSH. This would, of necessity, exclude individuals with subclinical hypothyroidism from the study. However, this would represent a majority of patients receiving LT4, and perhaps such individuals could be targeted in a separate study. Other patient groups are those who are surgically athyreotic and those individuals with thyroid cancer who have received radioactive iodine therapy after thyroidectomy, who might theoretically have the lowest T3 levels due to complete absence of endogenous thyroid function, and would require $\sim 1.7 \mu \mathrm{g} / \mathrm{kg}$ per day. Of note, only patients with thyroid cancer who are being managed to achieve a normal TSH would be considered eligible. In addition, the study should be adequately powered to examine treatment effects in important subgroups such as heterozygotes or homozygotes for the Thr92Ala polymorphism of the D2.

Consideration could be given as to whether patients who have low serum T3 levels while taking LT4 monotherapy should be targeted, and whether results should be stratified according to the change in serum T3 levels achieved with combination therapy. Neither baseline serum T3 levels nor serum T3 levels while on therapy seemed significant with respect to preference for combination therapy in one small study. However, this study was not prospectively conducted and the timing of blood sampling was not standardized [68]. Similarly in the study of DTE [58], the mean trough serum T3 level documented was $\sim 130 \mathrm{ng} / \mathrm{dL}(1.99 \mathrm{pmol} / \mathrm{L})$ during DTE therapy, both in those who preferred DTE and in those who had no preference. In one of the randomized crossover studies of combination therapy, no relationship was found between serum TSH, fT4 index, and fT3 index at baseline and QoL at baseline, or between the baseline thyroid function parameters and preference for combination therapy (e.g., baseline TSH $1.48 \mathrm{mIU} / \mathrm{L}$ in those preferring combination therapy versus $0.97 \mathrm{mIU} / \mathrm{L}$ in those without preference [ $p=0.49]$ ] [23]. Regardless of whether patients were eligible for a clinical trial of combination therapy based on low serum T3 levels, or whether results were stratified by the magnitude of the change in serum T3 levels, timing of blood sampling would need to be standardized to measure trough levels of serum T3 (see also discussion in Topics 5 and 6).

One recent study suggested that elevated thyroid peroxidase antibodies might be associated with dissatisfaction with LT4 therapy [69]. In this study of patients with elevated antibody titers, patients who underwent thyroidectomy and had a decline in thyroid peroxidase antibodies reported improved general health on the Short Form36 Health Survey (SF-36), compared with patients who
22

Eur Thyroid J 2021;10:10-38 DOI: $10.1159 / 000512970$
Jonklaas et al. 
did not undergo thyroidectomy. Thyroid peroxidase antibody titers could also be documented and would hopefully be balanced between groups by randomization.

Other participant eligibility criteria, which have mostly been utilized in the studies already conducted, include adults (i.e., exclusion of the pediatric population), a normal serum TSH at baseline, and a stable LT4 dose requirement. Individuals planning a pregnancy, currently taking T3-containing therapies, and those with unstable cardiac disease, active malignancy, or uncontrolled psychiatric disorders would be excluded. However, to ensure that the trial results were generalizable to the typical hypothyroid population, patients with comorbidities should be included. This might involve, for example, including patients with diabetes, controlled hypertension, pulmonary disease, stable cardiac disease, and treated depression. Thus, this would require a careful consideration of inclusion versus exclusion criteria and careful emphasis on monitoring of safety parameters during the trial.

Summary statements

- The randomized controlled trials comparing combination LT3/LT4 therapy did not specifically recruit patients with attention to persistent hypothyroid symptoms or dissatisfaction.

- It is possible that those individuals most likely to benefit from combination therapy may not yet have been included in trials in sufficient numbers to provide adequate power for detecting a response.

Topic 5: T3/T4 Dose Equivalence - Clinical and Trial Data (Presenter at Live Conference: F.S.C., Topic Summarizer: J.J.)

\section{T3 Levels during LT4 Monotherapy versus LT4/LT3} Combination Therapy

As previously mentioned, treatment of hypothyroidism with LT4 as an exogenous prohormone does not recapitulate the serum $\mathrm{TH}$ profiles seen in individuals with native euthyroidism $[9,70]$. Although serum TSH levels can be normalized, this occurs at the expense of elevated fT 4 levels, an elevated fT4/T3 ratio, and low/lower T3 levels [10-12]. Despite the low T3 levels seen with LT4 monotherapy, the T3 levels achieved are, in fact, stable, presumably reflecting that conversion is a regulated step [9]. With combined therapy with LT4 and LT3, the endogenous conversion step is partially bypassed. However, the amount of LT3 administration that results in no de- iodination of T4 to T3 is not known. When therapy with LT3 is added to LT4 therapy, measured T3 levels fluctuate depending on the dosage regimen (dose, timing, and frequency) used. With once-daily LT3 doses of 6.5-10 $\mu$ g, up to a $40 \%$ increase in T3 levels can be seen after the LT3 tablet is taken [57, 71]. Serum T3 increases of $23-36 \%$ were seen in two patients taking part in the trial of DTE at $3 \mathrm{~h}$ after the DTE was administered [58].

Although the protocol for a combination LT4/LT3 therapy study clearly needs to include monitoring of serum T3 levels, there are some caveats with measuring total T3 and more particularly fT3. Immunoassays commonly used for measuring both $\mathrm{fT} 3$ and T3 are more inaccurate than less commonly used tandem mass spectrometry assays [72], and tend to overestimate T3 levels at low concentrations. T3 levels are affected by patient age, patient comorbidities, and time of day. In addition, T3 levels are greatly affected by caloric/carbohydrate intake, patients who are restricting calories may have low serum T3 concentrations, and, in rodent models, the mechanism appears to be an effect of insulin on D2 activity [73]. In future studies, measurement of $\mathrm{T} 3$ rather than fT3 may be preferable simply due to better assay performance at higher hormone concentrations. In addition, trough levels of T3 are most likely easier to measure, due to the inherent variability in the magnitude and timing of the T3 peak. Associated TSH levels would be at the upper limit of their excursion (Fig. 5).

\section{T3 Levels during LT3 Monotherapy}

If LT3 monotherapy is employed, the endogenous peripheral T4 to T3 conversion is completely bypassed. LT3 monotherapy given once daily produces unacceptably high-peak serum T3 levels [74]. LT3 monotherapy administered three times daily produces stable TSH levels with continued fluctuations in T3 levels, such that they reach the upper end of the normal range with each of the three dose administrations $[75,76]$. Moreover, as judged by the length of time that it took over the course of the study to reach and maintain the goal TSH, it is too frequent a dosing regimen for participants to easily adhere to. LT3 monotherapy has differential effects on certain clinical indices compared with LT4 monotherapy. Treatment with LT3 alone was associated with lowered total and low-density lipoprotein cholesterol and decreased body weight, presumably reflecting the action of T3 on lipid and energy metabolism. Sex hormone-binding globulin was also significantly increased, reflecting the hepatic impact of LT3 [75]. Based on these LT3 monotherapy studies, it was estimated that in terms of therapeutic 


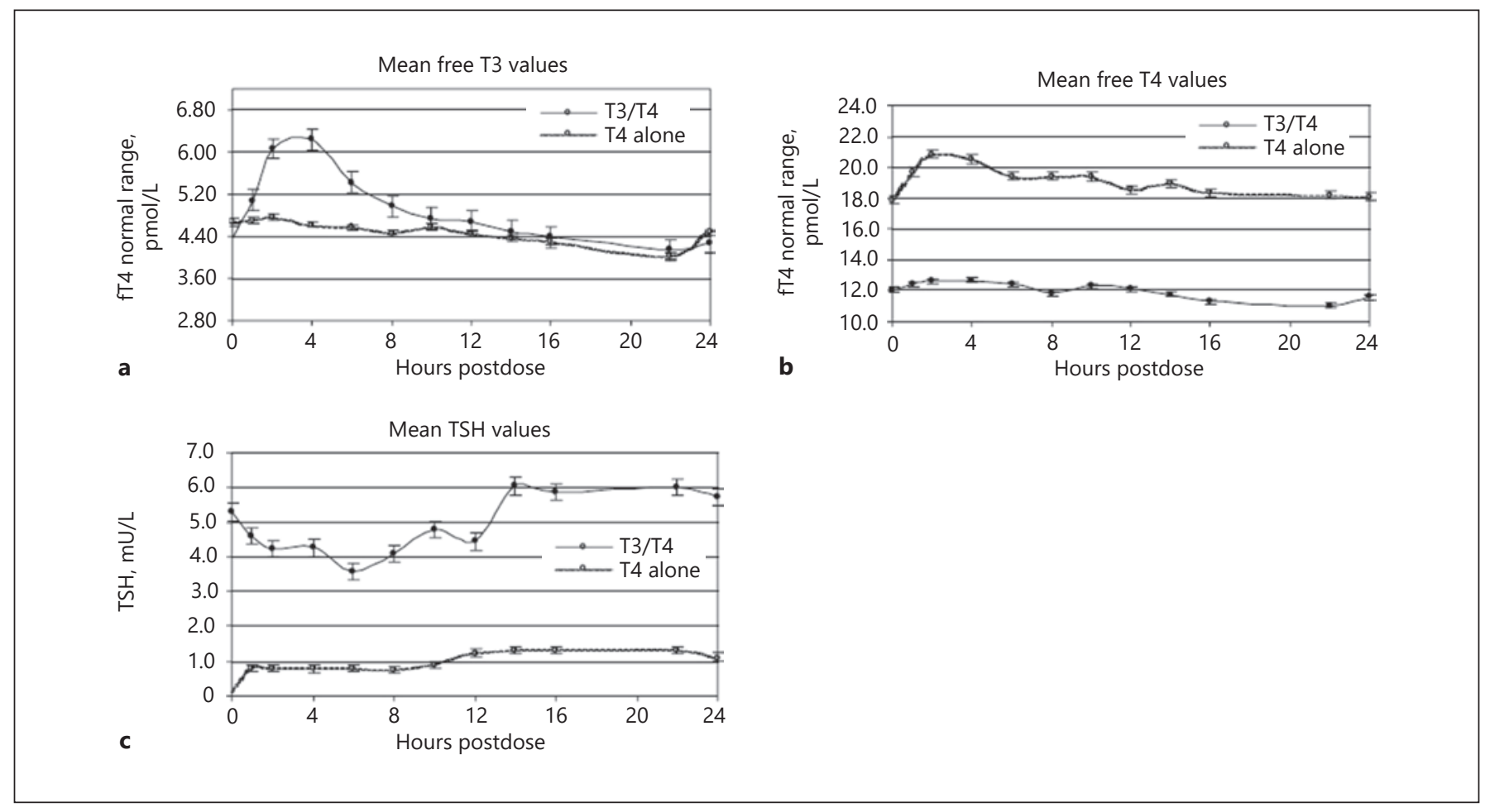

Fig. 5. Thyroid hormone profiles for $24 \mathrm{~h}$ after administering either LT4 or LT4/LT3 in 10 patients with hypothyroidism with mean values of fT3 (a), fT4 (b), and TSH (c) shown. Reprinted with permission from Saravanan et al. [57].

equivalence, LT3 could be substituted for LT4 at a 1-3 ratio, such that $40 \mu \mathrm{g}$ LT3 was equivalent to $115 \mu \mathrm{g}$ LT4 [76].

\section{T3 Pharmacokinetics}

Pharmacokinetic studies have shown that the time to maximum concentration (Tmax) of $\mathrm{T} 3$ ranges from $1.8 \mathrm{~h}$ [77] to $2.4 \mathrm{~h}$ [74], and the maximum observed concentration (Cmax) ranges from $292 \mathrm{ng} / \mathrm{dL}(4.48 \mathrm{pmol} / \mathrm{L})$ [74] to $320 \mathrm{ng} / \mathrm{dL}$ (4.92 pmol/L) [77], using daily doses of 30-45 and $50 \mu \mathrm{g} \mathrm{LT3}$, respectively. These same studies have shown that the half-life of LT3 is $22 \mathrm{~h}$ [74] or $22.9 \mathrm{~h}$ [77], clearly supporting the need to administer LT3 more than once a day to maintain reasonably stable serum T3 concentrations.

Of the 14 combination therapy trials that have been completed, 10 employed once-daily LT3 administration $[23,46,47,49,51,52,59,71,78,79]$, 4 employed twicedaily LT3 therapy $[17,48,53,60]$, and none used three times a day LT3 therapy. Assuming that three times daily LT3 administration is too onerous to be used in future trials $[75,76]$, and considering that a sustained-release preparation is not yet available for clinical use [80-83], twice a day therapy may be the most reasonable option. Given that twice-daily LT3 therapy, although not ideal with respect to the T3 fluctuations produced, is likely to be the best compromise, modeling studies provide information about potential twice-daily LT3 doses that could be utilized $[67,77]$. Although an argument could be made that further trials of combination therapy should not be conducted until a sustained-release preparation is available (see Topic 6), it seems likely that even studies already conducted using twice-daily LT3 were not optimized with respect to other aspects such as patient selection and length of trial, and, therefore, meaningful results might still be anticipated from an optimally designed trial of twice-daily LT3.

\section{Modeling of LT4/LT3 Combination Therapy}

Depending on the various estimates, the intact thyroid gland produces $\sim 85-100 \mu \mathrm{g}$ per day of T4 and 5-6.5 $\mu \mathrm{g}$ per day of T3. This results in the direct thyroidal production of T4:T3 in approximately a 14:1 ratio, which could be translated into the assumption that administered $\mathrm{TH}$ 
replacement should be provided as a $14: 1$ ratio of $\mathrm{T} 4$ to $\mathrm{T} 3$ to be physiological. Type 1 and 2 deiodinases convert the precursor T4 into T3, producing another $26.5 \mu \mathrm{g}$ of T3 daily. One modeling study estimated for the case of a $72.5 \mathrm{~kg}$ individual without endogenous thyroid function that $92.5 \mu \mathrm{g}$ LT4 combined with $3.25 \mu \mathrm{g}$ LT3 twice daily would produce relatively stable levels of T3 with oscillations in the order of 17\% [77]. The use of $88 \mu \mathrm{g} \mathrm{LT} 4$ and $5 \mu \mathrm{g}$ LT3 twice daily, and $62.5 \mu \mathrm{g}$ LT4 and $10 \mu \mathrm{g} \mathrm{LT} 3$ twice daily predicted a greater magnitude of T3 fluctuations of 44 and $88 \%$, respectively. Another modeling study predicted similar dosing regimens [67]. For a $70 \mathrm{~kg}$ patient with $<10 \%$ residual thyroid function, $100 \mu \mathrm{g}$ LT4 once daily and 5-6.25 $\mu \mathrm{g}$ LT3 twice daily kept T4 and T3 levels within the reference intervals. For a patient with $10-20 \%$ residual thyroid function, $100 \mu \mathrm{g}$ LT4 once daily and 3.75-5 $\mu \mathrm{g}$ LT3 twice daily kept T4 and T3 within their respective normal ranges. When a patient has $>20 \%$ residual thyroid function, then $87.5 \mu \mathrm{g}$ LT4 daily and $3.75 \mu \mathrm{g}$ LT3 twice daily would be expected to maintain normal TH levels.

\begin{tabular}{|l|}
\hline Summary statements \\
\hline - $\begin{array}{l}\text { LT4 monotherapy administered once daily generally } \\
\text { produces stable low-normal T3 levels, with low levels being } \\
\text { seen in some thyroidectomized individuals. }\end{array}$ \\
\hline $\begin{array}{l}\text { LT4 monotherapy administered once daily produces } \\
\text { increased T4/T3 ratios, compared with native } \\
\text { euthyroidism. }\end{array}$ \\
The pharmacological equivalence of LT3 to LT4 is \\
approximately a 1:3 ratio. \\
\hline $\begin{array}{l}\text { LT4/LT3 combination therapy with LT3 given once daily } \\
\text { produces up to } 40 \% \text { increase in serum T3 levels above } \\
\text { trough levels. }\end{array}$ \\
$\begin{array}{l}\text { LT4/LT3 combination therapy is expected to produce } 17, \\
\text { 44, and } 88 \% \text { fluctuations in serum T3 levels when 3.25, } 5, \\
\text { and } 10 \mu \text { LT3 twice daily, respectively, is used. }\end{array}$ \\
\hline
\end{tabular}

Topic 6: Target T3 and TSH Levels and Slow-Release T3 (Presenter at Live Conference: C.M.D., Topic Summarizer: C.M.D.)

It has generally been assumed that dosing of LT4 alone and LT4/LT3 combinations for individuals on TH replacement should be titrated versus serum thyroid parameters using criteria for "optimal levels" that are the same as those used to assess thyroid function in healthy individuals with an intact HPT axis. Specifically, the assumption has been that a TSH in the reference range is the most important and sensitive parameter in assessing for euthyroidism, and the measurement of TH levels is secondary and generally not required if TSH is "normal." There is not universal agreement about this approach [84, 85]. Moreover, this approach makes several assumptions that may deserve reconsideration. For example, a recent meta-analysis suggested that fT4 levels were more associated with clinical parameters such as atrial fibrillation, osteoporosis, cancer, and dementia than with TSH values even within the reference range [86].

\section{The fT3:fT4 Ratio Is Altered on TH Replacement with}

LT4, Even with Similar TSH Levels

Gullo et al. [11] showed that in 1,811 athyreotic individuals on LT4 replacement that the fT3:fT4 ratio (0.24, interquartile range $0.20-0.28$ ) was significantly lower than in 3,875 normal individuals with an intact HPT axis (0.32, interquartile range $0.27-0.37), p<0.001$, despite similar TSH levels (1.2 mU/L vs. $1.4 \mathrm{mU} / \mathrm{L})$. As noted by Bianco in Topic 1 discussed earlier, increased T4 levels inhibit the activity of the D2 deiodinase that is essential for activation of TH in peripheral tissues, but this effect is much less pronounced in the hypothalamus/pituitary. Hence the reduced fT3:fT4 ratio during T4 replacement may result in efficient "normalization" of TSH while reducing generation of active T3 in other tissues of the body (through D2 inactivation). The relationship of TSH with peripheral tissue thyroid function may thus be distorted in LT4 replacement alone with reduced fT3:fT4 ratios. Another example of nonphysiological TH levels, although occurring in the opposite direction, is the low fT4 levels that are achieved with DTE [58], the impact of which on deiodinase action does not appear to have been reported.

\section{Serum T3 and T4 May Not Have Interchangeable} Function

Around 25\% of normal children have an fT3 level above the adult reference range [87]. fT3 levels in childhood correlate positively with fat mass and age of onset of puberty, whereas fT4 (or TSH) levels have no such correlation [87], suggesting that circulating T3 levels may have different functions to T4. Furthermore, in children and adults with an intact HPT axis, fT3 levels do not correlate with TSH levels (and in children they show a positive rather than the negative correlation seen with fT4) $[11,87]$. Hence, TSH may not faithfully represent all aspects of thyroid status, especially those conferred by fT3 alone. Some of these considerations may be relevant to 
use of combination therapy with LT4/LT3 in adults. The relative contribution of $\mathrm{T} 3$ and $\mathrm{T} 4$ to regulating $\mathrm{TSH}$ levels needs to be better understood, especially during exogenous combination therapy and the greater pulsatility of fT3 levels compared with fT4 levels.

\section{Assessing Thyroid Status with "Pulsatile" T3 Levels on} LT3 Replacement May Be Different

Fluctuations in serum T3 are relatively narrow within individuals with endogenous thyroid functioning [88]. As discussed in Topic 5, the short half-life of T3 means that dosing even three times a day results in significant hourly fluctuations that are not seen in individuals with an intact HPT axis receiving LT4 alone (Fig. 5). This leads to two problems. First, it is not clear which serum T3 level should be used to assess appropriate dosing - trough or peak - and how this should be compared with "reference levels" from individuals with an intact HPT axis. For example, if peak levels are above the "reference range" but trough levels are in the lower part of the reference range, is this "overdosing" or "underdosing?" Trough levels are most likely easier to measure, because of the inherent variability in the magnitude and timing of the T3 peak. If the goal is to achieve physiological fT3/fT4 ratios for the reasons already discussed above and in Topic 1, this cannot be achieved in presence of pulsatile T3 levels as fT3/ fT4 levels will depend on the timing of sampling in the day. Second, it is not clear whether "pulsatile" T3 levels during LT3 dosing have different effects on T3 action, in both pituitary and elsewhere. There are little data to inform this, but if "pulsatile" T3 has a greater effect on TSH suppression than a similar amount of T3 distributed evenly throughout the 24-h period, this could explain why the trials that showed a preference for LT3 in combination with LT4 were generally associated with lower, sometimes "subnormal" TSH levels [89]. In support of this, it is noted that in the Thyroid Epidemiology, Audit, and Research (TEARS) retrospective review of patients in Scotland, of 400 individuals using LT3, compared with 33,995 patients taking LT4, no excess of cardiovascular disease including atrial fibrillation was noted despite TSH levels being substantially lower in LT3 users (1.07 vs. 2.08 $\mathrm{mIU} / \mathrm{L}, p<0.001)$, suggesting that a lower TSH on LT3 therapy does not necessarily reflect over-replacement [38]. Some limitations of these data could include the age discrepancy of participants (mean age of 48 years in the LT3 group compared with 60 years in the LT4 group) and potential for some selection bias as patients in the LT4 group had a higher prevalence of pre-existing cardiovascular disease before starting TH treatment.
The Requirement for Use of a Slow-Release

Preparation in Future Trials of T4+T3

For the reasons already given, it is argued that to both monitor T3 dosing and use TSH as a reliable measure of appropriate dosing, a slow-release T3 preparation is required and should be the goal of future trials. Recently, Santini et al. [81] demonstrated using T3 sulfate as a slowrelease preparation that combination T4/T3 therapy could restore a near-normal fT3:fT4 ratio with reference range TSH levels. Hence, to optimize the pharmacodynamics of LT4/LT3, it is, therefore, proposed that the target for titration in future trials should be to achieve a physiological fT3:fT4 ratio (mean $=0.32$, interquartile range $0.27-0.37$ ) in the presence of physiological TSH levels (e.g., $1.4 \mathrm{mU} / \mathrm{L}$ ). However, it should be noted that individual dose titration is likely required to achieve this. Such a ratio could most easily be achieved using a slowrelease preparation of T3. Use of DTE would not allow such a ratio to be achieved. The therapeutic substitution of LT3 for LT4 has previously been calculated to approximate a 1:3 ratio, as discussed in Topic 5 [76], but it is not clear whether this ratio would also apply to a sustainedrelease preparation.

\begin{tabular}{|l|}
\hline Summary statements \\
\hline $\begin{array}{l}\text { Monitoring serum T3 levels and fT3/fT4 ratios on } \\
\text { conventional LT3 preparations is problematic due to } 24 \mathrm{~h} \\
\text { variation. }\end{array}$ \\
\hline - $\begin{array}{l}\text { Interpretation of TSH levels on conventional LT3 } \\
\text { preparations may also be problematic. }\end{array}$ \\
\hline - $\begin{array}{l}\text { Physiological dosing of LT3 is difficult to achieve using } \\
\text { conventional T3 preparations. }\end{array}$ \\
\hline $\begin{array}{l}\text { Slow-release T3 preparations are required to achieve } \\
\text { physiological fT3/fT4 levels. }\end{array}$ \\
- $\begin{array}{l}\text { Slow-release T3 preparations are required to achieve } \\
\text { physiological TSH levels in combination with physiological } \\
\text { fT3/fT4 levels. }\end{array}$ \\
\hline
\end{tabular}

Topic 7: Psychological and QoL Measures (Presenter at Live Conference: T.W., Topic Summarizer: J.J.)

\section{Generic versus Topic-Specific Health-Related QoL} Measures

Health-related QoL has been defined as "the subjective assessment of the impact of disease and its treatment across the physical, mental and social domains of functioning and well-being" [90]. Generic PRO QoL measures
Jonklaas et al. 
(e.g., SF-36, Hospital Anxiety and Depression Scale, Beck Depression Inventory [BDI], and GHQ) typically have very well-documented measurement properties confirmed across many studies and can be used to compare across disease groups. By contrast, disease-specific PROs (e.g., Zulewski score, TSQ) and Thyroid-Related Quality of Life Patient-Reported Outcome ThyPRO (a comprehensive thyroid-related PRO that measures the impact of any benign thyroid disease on health-related QoL) are typically more responsive to change (e.g., a change in therapy). There is also evidence that the domains that patients and clinicians consider to be important in thyroidrelated QoL are different [91] (online suppl. Table 4). Fatigue is a top-ranked concern for patients with thyroid disease in general, with general fatigue, physical fatigue, and mental fatigue being ranked number 1,3 , and 4 , respectively [91]. As the mental and physical fatigue scores of a generic PRO such as the SF-36 typically do not change in the LT4/LT3 combination trials, it is possible that hypothyroidism is associated with a different quality of fatigue to patients with other conditions such as cancer, diabetes, heart failure, and arthritis, for whom the SF-36 is a better predictor.

Of these PROs, the ThyPRO has the widest coverage of the range of thyroid QoL-related issues [92]. In a systematic review of the quality of thyroid-specific healthrelated QoL instruments, the ThyPRO questionnaire was recommended for studying patients with hypothyroidism [93]. Validated versions include the full 85-item ThyPRO [64, 94-97] and the 39-item ThyPRO-39 scale with the 22-item ThyPRO Composite QoL scale [98]. The ThyPRO-39 Composite QoL scale is based on 22 items from the Tiredness, Cognition, Anxiety, Depressivity, Emotional Susceptibility, Impaired Social Life, Impaired Daily Life, and Overall QoL scales of ThyPRO. This short version of ThyPRO 39 shows comparable reliability and validity with the original ThyPRO [98], and could easily be used in a future clinical trial of combination therapy.

An alternative approach to a symptom-based endpoint not used in prior combination therapy studies would be to ascertain which two to three symptoms an individual patient has, which they attribute to their hypothyroidism and consider most important, and ask the patient to rate these symptoms on a visual analog scale at various points during the course of the combination therapy trial. The symptoms would be patient specific, but the change in symptoms could nevertheless be determined. Although there have been previous attempts to utilize this approach, it has not acquired wide acceptance or use [99, 100]. In a noncontrolled study that solicited input from

Combination Therapy Consensus

Statement patients about their treatment for hypothyroidism, fatigue, weight management, and memory or other problems with thinking were the chief concerns [101].

\section{How Is a Good PRO Defined? Content Validity and Responsiveness}

Minimum standards are recommended for PROs [102] in multiple domains. When considering a trial of therapy for hypothyroidism, there are two key measurement properties of major importance. First, "content validity" - does the PRO have "evidence that patients and experts consider the content relevant and comprehensive for the concept, population, and aim of the measurement application?" In the LT4/LT3 study of Appelhof et al. [53], no significant change in the PRO used was seen, but patients more frequently expressed a preference for the combination. This could be because the PRO "missed the target" by not measuring the aspects of life that the patients experienced as having improved. To ensure content validity, a qualitative study involving patient interviews could first be conducted. Patients could be selected for interview, for example, if they are dissatisfied with LT4 therapy, or if they have previously had a positive experience with combination therapy. If the items that patients identify are not contained within existing PROs, they could be added to a redesigned PRO. The second domain to consider is "responsiveness," that is the "the extent to which a PRO measure can detect changes in the construct being measured over time." This has a significant impact on the power of the study (see section on powering studies on the next page).

\section{Prior Use of PROs in Studies of LT4 or LT4/LT3 \\ Therapy}

PROs used in prior randomized trials of combination therapy have mostly been generic PROs, such as the BDI, the Profile of Mood States, symptom checklist-90, and the SF-36 in four trials each, and the GHQ in three trials. Three trials of synthetic combination therapy $[17,47,52]$ and one of DTE [58] have used thyroid-specific PROs.

ThyPRO measures tiredness using seven items each scored on a 5-point scale, all subsequently reflected in the tiredness scale. When patients with hypothyroidism were compared with the general population, tiredness was one of the parameters that showed the most difference between the populations, with a large effect size [66]. In an uncontrolled prospective study of the initiation of LT4 therapy for mild hypothyroidism (TSH values 5.5-12.2 mIU/L), it was also one of the scales that showed the most improvement with treatment [66]. The cognitive complaints scale, al- 
though different from the general population, did not improve significantly with 6 months of LT4 treatment. ThyPRO-39 has been utilized to assess symptoms in a group of patients who reported reduced QoL despite treatment with LT4 to achieve a normal TSH. With initiation of combination therapy, with the LT3 administered twice daily, there was an improvement in both tiredness and cognitive complaints after both 3 and 12 months of treatment [103]. The 3-month improvement in QoL was not accompanied by a decrease in body weight. However, this study was an unblinded study without a control group. Anxiety and depression appeared to show little change in response to combination LT4/LT3 treatment, whereas "emotional susceptibility" showed a large change [103].

\section{Powering Studies Appropriately for PROs as Primary}

Outcome

In order for a study to be adequately powered based on the responsiveness, the minimal clinically important difference should, broadly speaking, be a third to a half of the standard deviation for an effect size of 0.3-0.5. Online supplementary Table 5 shows the study size of recent combination therapy studies versus the estimated sample size required for different effect sizes of 0.3 and 0.5 . Note that the majority of studies were underpowered and all were underpowered if a response can only be expected in $20 \%$ of participants.

\section{Patient Preference}

It is possible that the PROs may not adequately capture the elements that underlie patient preference. Each patient's response to therapy is likely to be heterogeneous with preference stemming from the balance of improved versus worsened symptoms. This may be addressed by a valid composite score from the candidate PRO ideally being the primary outcome, with subscales/ symptoms reported as secondary outcomes, to allow for differential effect on various aspects of QoL. Any future combination therapy trial should include assessment of patient preference for the therapeutic therapy regimen compared with the LT4 regimen before study initiation. Preference should be assessed at several time points during the study and at study completion to assess early and sustained responses. In addition, patients should be asked whether they believe they are receiving the combination therapy or standard LT4 therapy. They could also be asked to document the reason for their preference. Qualitative interviews might be considered in a subset of patients, to gain further insight into individual patient preferences.
To ensure that the assessment of patient preference is not biased, maintenance of the blinding of therapies in the trial is critical. There should be consideration for patient preference being one of the efficacy outcomes for any future trials of combination therapy. An unanswered question with respect to patient preference is whether preference for combination therapy might be associated with a stimulatory effect of LT3 exerted through T3 thyrotoxicosis, as might be seen with off-label use of LT3 for refractory depression. Comparison of T3 and TSH levels in those who preferred versus did not prefer combination therapy might shed some light on this issue. A recent analysis suggests that the salutatory effects of T3 may require higher T3 levels than the QoL or neurocognitive benefits [67]. It is also possible that if patients experience T3-related effects such as tachycardia or insomnia, they may realize that they are taking LT3 rather than placebo and "prefer" it on that basis.

\begin{tabular}{|c|c|}
\hline \\
\hline \multicolumn{2}{|c|}{ Summary statements } \\
\hline & $\begin{array}{l}\text { A thyroid-specific instrument should be used to measure } \\
\text { PROs. }\end{array}$ \\
\hline & $\begin{array}{l}\text { The selected PRO should have content validity by including } \\
\text { the most relevant and important aspects of a concept in the } \\
\text { context of a given measurement application. }\end{array}$ \\
\hline & $\begin{array}{l}\text { The selected PRO should be responsive so that it detects } \\
\text { changes in the construct being measured over time. }\end{array}$ \\
\hline & The selected PRO should be the primary study endpoint. \\
\hline & $\begin{array}{l}\text { The study should be adequately powered based on the } \\
\text { primary endpoint. }\end{array}$ \\
\hline
\end{tabular}

Topic 8: Biological Outcomes, Biomarkers, and Safety Measures (Presenter at Live Conference: A.R.C., Topic Summarizer: J.J.)

\section{Outcomes Considered in Prior Combination Therapy \\ Trials}

PROs with a focus on health-related QoL would be the primary efficacy outcomes. Patient preference should also be an important outcome and would be likely closely linked to health-related QoL. Several biological outcomes and safety measures have been monitored in the combination therapy studies conducted thus far and would
Jonklaas et al. 
serve as secondary efficacy and safety outcomes [104]. These measures have included body weight, lipid profile, blood pressure, sex hormone binding globulin, bone turnover markers, cardiac monitoring, bone mineral density, and neurocognitive function. When considering any changes in these parameters reported in the trials, it is important to take the duration of the trial into account. Eleven trials were 5-16 weeks [23, 46, 49, 51-53, 58-60, $71,79]$, three trials were $4-6$ months $[17,48,78]$, and one trial was 1 year in duration [47].

Body weight was slightly decreased in the combination therapy arm in two trials $[53,58]$, but although statistically significant, it is unclear whether the weight loss would be considered clinically significant in terms of a percentage decrease in body weight with associated health benefits. One of these two trials was the trial of DTE [58] and the other was the arm of the trial by Appelhof et al. [53] that used synthetic combination therapy at a 5:1 ratio of LT4 to LT3. Two trials showed a decreased cholesterol in the combination therapy arm $[53,78]$, while a third trial showed an increased cholesterol in the combination therapy group, but this group also had a higher mean TSH value [52]. Although blood pressure is generally considered an important clinical outcome, this parameter did not show a between-group difference in any of the prior trials [104]. Where measured, bone turnover markers (alkaline phosphatase, osteocalcin, and urinary deoxypyridinolines) were increased in two trials (including the Appelhof trial arm using the 5:1 LT4:LT3 ratio) $[53,78]$, and no different in two trials $[49,52]$. Resting pulse rate was increased in the combination therapy group in two trials (including the Appelhof trial arm using the 5:1 LT4:LT3 ratio) $[46,53]$, decreased in the combination therapy group in two trials $[49,52]$, and unaltered in the remaining trials in which it was assessed. Echocardiography parameters were basically unaltered in one trial that included this assessment [51]. Bone mineral density at the forearm was unchanged in the one trial in which it was measured [78]. Cognitive functioning was assessed in 11 trials, but with only 2 positive outcomes: there was superiority of combination therapy on multiple measures in one trial [46], and superiority of combination therapy on a minority of measures in one trial [49]. To achieve a valid comparison between the combination and monotherapy groups, there should be no clinically important difference in TSH between groups (bearing in mind the considerations about serum TSH discussed in Topic 6). This was not achieved in five trials, with two trials having a lower TSH in the combination therapy group (including the Appelhof trial in 5:1 ratio group) [53,71], and three

Combination Therapy Consensus

Statement trials having a higher serum TSH in the combination therapy group $[47,52,58]$.

\section{Outcomes to Be Considered in Future Combination} Therapy Trials

PROs with a focus on thyroid-related QoL should be the primary efficacy outcomes of any future trials. These outcomes have been addressed in the previous discussion of Topic 7. Patient preference would also be an important outcome (see Topic 7).

With regard to the design of future combination therapy trials, secondary efficacy outcomes in the following domains should be considered for inclusion in the trials: metabolic, cardiovascular, cognitive, and musculoskeletal. There should not be a clinically meaningful difference in TSH between groups to be able to make a meaningful comparison of the outcomes between the two therapies. As long as a new sustained-release T3 product is not being utilized [80-83], the outcome measures do not need to be selected with Food and Drug Administration approval in mind. The most important consideration for choice of outcome measure is whether this outcome is responsive to LT3 therapy within the range of acceptable T3 levels or T3 tissue actions. There are several steps before serum concentrations of THs mediate physiological effects. For this reason, one could argue that the physiologically measurable parameters (from heart rate to resting energy expenditure [REE] to body weight) allow much better assessment of a "normal" thyroid status. With this reasoning, these secondary parameters are important parameters and the serum concentration only a surrogate that is remote from where the action takes place. Therefore, the search for and validation of physiological parameters should be an important part of future trials.

Another consideration is the burden to the trial participant performing the measurement. To measure REE, a metabolic cart and appropriate participant preparation are required. Alternative approaches, for example, could include the use of whole room indirect calorimeters in a subgroup of patients to characterize in detail any effects of combination therapy on the various components of energy expenditure. Measurement of maximum rate of oxygen consumption measured during incremental exercise (VO2 max) might also be relatively burdensome. Other considerations include availability and standardization of the measure across trial sites. Cost is a key issue and this obviously increases depending on how many times the measure is reassessed during the trial. Outcomes that assess safety are essential. An appropriate statistical analysis needs to be devised to incorporate the various measures chosen. 
Potential Secondary Efficacy Outcomes

Metabolic efficacy outcomes could include body weight, waist circumference, REE, activity monitoring, lipid profile, and sex hormone-binding globulin. Cardiovascular efficacy outcomes available include lipid profile, resting pulse, blood pressure, echocardiogram, brachial artery flow, VO2 max, and carotid intimal media thickness. For cognitive efficacy outcomes, a number of scales assessing executive function are available, including the NIH Toolbox Cognition Battery $[105,106]$. The fluid cognition composite score includes five tests (attention and executive function, episodic memory, working memory, executive function, and processing speed) that measure "fluid abilities" [106]. These are important for adapting to new situations in everyday life and are more likely to be affected by metabolic processes and aging than cognitive functions that are more dependent on past exposure (crystallized abilities). Potential musculoskeletal efficacy outcomes include bone biomarkers such as C-telopeptide or N-telopeptide, dual-energy X-ray absorptiometry scan for bone density and body composition, hand grip strength, and tests of physical function such as the short physical performance battery and the $400 \mathrm{~m}$ walk. The trial also has to be of sufficient length to allow for changes in the parameter being assessed to take place, such that longer duration trials of 6 or 12 months are likely to be needed. With respect to safety, hyperthyroid symptoms, tachycardia, atrial fibrillation, and decreased bone density and fracture would all be relevant. Cardiac safety could be assessed using electrocardiograms or 2 weeks cardiac monitors. Some of the efficacy outcomes would additionally be measures of safety, such as bone mineral density measurement.

Secondary efficacy outcomes that could be included in future trials without excessive cost and without undue burden for study participants are shown in the supplementary material, along with potential safety measures (online suppl. Table 6). Safety measures should include hyperthyroid symptoms, adverse events, and cardiac arrhythmia monitoring. Monitoring for cancer progression (e.g., breast cancer) could be considered. For some of these secondary outcomes, a reasonable approach might be a consideration of "proof-of-concept" studies to assess the preliminary point estimates of the intervention and to characterize the effects on secondary endpoints (online suppl. Table 6). Such pilot trials needed to explore additional outcomes of secondary importance as well as relationships between variables could either be conducted as separate pilot studies or could be conducted within a larger trial. The advantage of inclusion as a nested study with- in a larger study is that this could avoid delay of the larger study. For example, rather than a design in which all the patients undergo REE measurements, these measurements could be conducted for a small subgroup, thus producing important data.

\begin{tabular}{|l|}
\hline Summary statements \\
\hline - \\
$\begin{array}{l}\text { THs impact metabolic, cardiovascular, cognitive, and } \\
\text { musculoskeletal parameters. }\end{array}$ \\
\hline - $\begin{array}{l}\text { Serum TH levels are only a surrogate marker and may not } \\
\text { reflect what is taking place at the cellular level. }\end{array}$ \\
\hline - $\begin{array}{l}\text { Physiologically measurable parameters (such as heart rate, } \\
\text { body weight, and REE) are the ultimate reflection of TH } \\
\text { action in cells and allow for assessment of a euthyroid state. }\end{array}$ \\
- $\begin{array}{l}\text { Assessments of metabolic, cardiovascular, cognitive, and } \\
\text { musculoskeletal parameters should be included in clinical } \\
\text { trials of combination therapy. }\end{array}$ \\
\hline
\end{tabular}

Topic 9: Trial Design Considerations (Presenters at Live Conference: Several, Topic Summarizer: J.J.)

\section{Randomization, Placebo Control, Blinding, and Thyroid Analyte Assay Standardization}

Although the position could be taken that no future trials should take place without using a sustained-release T3 preparation, there appear to be sufficient flaws in previously conducted studies, that a new optimally designed study of LT3 should take place. Examples of flaws in prior studies include short duration, once-daily LT3 therapy, nonphysiological T4:T3 ratios, and, with three exceptions [17, 47, 52], failure to use a thyroid-specific patient-reported outcome. If there is agreement that there is equipoise for a new clinical trial using the short-acting LT3 preparations currently available, it is clear that any future trial should be randomized, placebo-controlled, and blinded to the participant and investigator. Use of a randomized controlled trial would allow for matching for important parameters such as sex, hormone replacement status, and menopausal status. Maintenance of blinding, either through generation of identical placebos or overencapsulation, is important for maintaining the study integrity. In addition, both participant and investigator would need to be blinded to the participant's serum fT 4 and T3 concentrations. Blinding would be confounded if participants experienced manifestations of high serum T3 levels such as palpitations or insomnia. In addition to randomization, placebo control, and blinding, a key element in a rigorous trial would be standardization of the assays used to measure TSH, fT4, and T3. Given the intra-assay and interassay
Jonklaas et al. 
variation between $\mathrm{TH}$ immunoassays, ideally all laboratory measurements would need to be performed in a combined batch in a centralized laboratory facility. Parallel laboratory testing for adjustment of $\mathrm{TH}$ doses and safety measures could be performed at a local level.

\section{Length of Trial}

Considering that $\mathrm{TH}$ replacement is a lifelong therapy, and that for LT4 adjustments a steady state is reached after 6 weeks following dose adjustment, a long observation period (12 or 24 months) would be ideal. Only one prior study was of 12 months duration [47]. The duration of the trial should be at least 1 year to assess persistence of efficacy and safety over sufficient duration. A long study duration would also allow for therapy adjustments, and also allow for gathering data on potential toxicity, such as on the cardiac and skeletal system. However, a drawback to a long study is reluctance to enroll in a long study and the potential dropouts from the study that may accrue over time. A study duration of 9 months might be a compromise and would be longer than the duration of all except one of the already published studies. Study duration should be greater than 4 months, given that a placebo effect may persist for as long as 4 months [17]. Other than the case of a clinical trial of a sustained-release T3 preparation, since short-acting LT3 is commercially available, one can expect significant attrition during the study, with participants who do not experience the expected improvement being likely to withdraw from the study to request prescribing of LT3 or DTE by their providers.

\section{Crossover versus Parallel Design}

A crossover design is appealing because of the increase in statistical power due to the ability to perform paired analyses, as has been performed in prior studies $[23,46,50,52$, $58,59,75,76,107]$. A crossover design may also be more attractive to participants as they know they will receive LT3 during the course of the study. However, disadvantages include the potential carryover effect of the first study therapy on the second arm of therapy, loss of data with any dropouts, and the difficulty conducting a trial of sufficient duration. Overall, a parallel design is preferred due to the long study duration and concerns about carryover effects and the impact of dropouts in a crossover design.

\section{Therapies to Be Studied and Relative LT3 Dose}

Prior trials of synthetic TH therapy have compared combination therapy with LT4/LT3 with monotherapy with LT4. There is one published trial comparing DTE with LT4. DTE therapy is thus understudied and a trial comparing three therapies (synthetic LT4/LT3, LT4, and DTE) could be considered. The microgram ratio of T4:T3 in these studies ranges widely from 4:1 to 19:1 (Table 2). Thus, not only are many of the doses employed supraphysiological with respect to their LT3 content, but also this variation adds to the heterogeneity of the trials, and the possibility of salutatory effects of LT3. DTE might be attractive to participants, as there is considerable interest in DTE expressed by patients and patient advocacy groups, and DTE is preferred by many patients in uncontrolled studies $[101,108]$. Inclusion of DTE would, however, add to cost, trial size, and complexity, and perhaps the need for additional safety monitoring because of the high T3/T4 ratio contained in the DTE. Overencapsulation may be the preferred means of masking the study drug to avoid patients potentially identifying DTE based on its aroma or taste. The resultant tablets should be of identical smell and taste, and, if possible, tamper proof.

\section{Superiority versus Noninferiority Trial}

To change the status quo and identify a reason for using LT3, rather than maintaining therapy with LT4, a trial designed to show superiority seems desirable. If a noninferiority trial was solely examining safety, then it could demonstrate that combination therapy (performed in a controlled manner) does not cause harm to patients. An equivalence trial could also make sense if the therapeutic options were equal in cost and ease of use. However, it may not make sense currently as combination therapy is more complicated to use (i.e., dosing multiple times per day), more expensive, and requiring more careful surveillance of multiple $\mathrm{TH}$ measures. Easy use of LT3 could occur in the hypothetical circumstance of a new sustained-release $\mathrm{T} 3$ tablet that could be taken once a day or less often, and was similar in cost or cheaper compared with LT4.

\section{Etiology of the Hypothyroidism}

Surgically athyreotic individuals, and those with thyroid cancer who have received thyroidectomy and radioactive iodine treatment and who are being managed to maintain a normal TSH, would be ideal trial participants due to their absence of endogenous thyroid function. However, studying this group only would reduce the generalizability of the trial, as Hashimoto's thyroiditis is the most common cause of hypothyroidism, and these patients may be different from athyreotic patients based on their TH levels, but also based on other characteristics such as fatigue [109]. Including both patients with autoimmune thyroid disease and those with hypothyroidism due to removal or destruction of the thyroid would be ide- 
al, with stratification of the analysis by group. Patients with thyroid cancer requiring TSH suppression would likely need to be studied separately due to the additional consideration of their iatrogenic hyperthyroidism. Although subclinical hypothyroidism is more common than overt hypothyroidism, participants with this diagnosis should probably be excluded from an initial future trial due to their retention of endogenous thyroid function and possible difficulty attributing their symptoms to thyroid disease. However, this too would reduce the generalizability of the findings, as the majority of patients taking LT4 are being treated for subclinical hypothyroidism [110].

\section{Pragmatic Trial Design}

Many patients with hypothyroidism also have other chronic medical conditions [13]. If individuals with comorbidities are excluded from a future clinical trial, there is a risk that the results of the trial will not be generalizable to most of the hypothyroid population. Therefore, a balance needs to be achieved by allowing individuals with, for example, well-controlled hypertension, diabetes, and cardiac disease, as well as stable and monitored psychiatric disease such as depression, to be eligible for the trial, but excluding individuals with uncontrolled diabetes, unstable coronary artery disease, active malignancy, or unstable psychiatric disease. Recognized indices of the burden of disease or comorbidities could be utilized to standardize exclusions (e.g., Charlson score and Individual Burden of Illness Index for Depression). Women with varying statuses with respect to estrogen replacement and menopause would also need to be included.

\section{Subgroup Analyses}

Subgroup analyses, such as by sex, age, estrogen replacement status, menopausal status, presence of comorbidities, genetic polymorphisms, and thyroid peroxidase antibody positivity, should be prespecified.

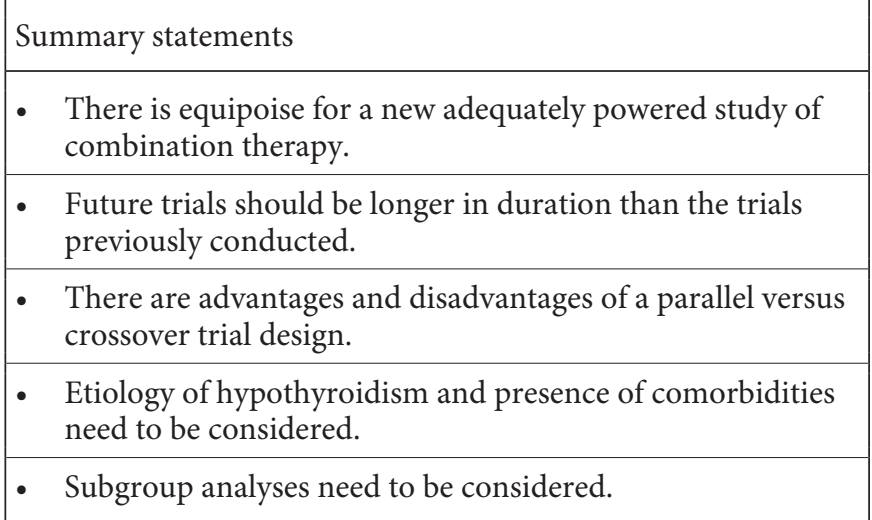

Topic 10: Incorporation of Patient Experiences

(Presenter at Live Conference: E.A.M. and Patients, Topic Summarizer: J.J.)

\section{Patient Descriptions of Their Experiences}

As part of this consensus conference, patients with hypothyroidism shared their experiences with their treatment, as we wished to incorporate the "patient voice" into our discussion of designing new trials. Two individuals shared their experiences during a formal panel discussion, others participated during the question-and-answer period. The two patients involved in the panel described certain symptoms of hypothyroidism that did not resolve with treatment. For one of these individuals, the residual symptoms were fatigue, weight gain despite an active lifestyle, and hair loss. These symptoms occurred with monotherapy despite the fact that this therapy achieved a normal serum TSH. Combination therapy improved this individual's energy and aided weight management, but also exacerbated menopausal hot flashes and caused a feeling of "being hit" after taking LT3 and then experiencing "the drop" later. The other individual continued to experience low energy and body aches while taking LT4, with only partial improvement of these symptoms with combination therapy. Other symptoms discussed included mental alertness and "brain fog."

Both patient participants valued their communications with their physicians, shared decision making, and continuity of care. They stressed the value to them of lifestyle modification with exercise and a healthy diet in improving well-being and aiding in weight control. They both stated the importance for them of adjusting their expectations of what their baseline should be for aging and their other comorbidities. They also acknowledged the challenges of distinguishing nonspecific symptoms associated with their comorbidities from symptoms remaining after treatment of hypothyroidism. Another opinion expressed during the question time was that the goal of treating hypothyroidism should be complete restoration of health, regardless of age, menopausal status, or any comorbidity. This expectation was of a greater magnitude than the expectation described by other patients who also shared their experiences.

Patients also discussed what resources were helpful to them for learning about hypothyroidism. There were a variety of opinions about the helpfulness of social media and lay blogs describing symptoms of hypothyroidism. Some patients described them as unhelpful, others felt that they were helpful as they validated their symptoms. One way in which social media was described as not beneficial was a case of an individual who was not experienc- 
ing the symptoms described, who, therefore, worried that something was amiss, or that this reflected a failure to be aware of ongoing symptoms.

\section{Choice of Therapy}

Patients also expressed a desire to be informed and to make good decisions regarding optimizing their health. In the setting of combination therapy not yet having been shown to be superior, patient-directed knowledge translation research may be needed to facilitate informing patents of the risks, benefits, and any uncertainties related to the choice of $\mathrm{TH}$ preparations, based on best available published evidence from trials. Factors such as safety profile, price, availability, and convenience may be important for different patients, including those with comorbidities and from different countries, and could be investigated in knowledge translation trials.

\section{Inclusion of "Preference" as an Outcome}

Preference for therapy was also discussed as being an important outcome. The finding that some trials did not show that combination therapy was beneficial with respect to QoL, mood, and cognitive outcomes, but nevertheless was preferred by some patients was postulated by patients to be due to some as yet unappreciated benefit that the trial was, therefore, not designed to measure.

\section{Physical Activity, Fatigue, Cognition, and Weight}

As described by the patients participating in the patient panel, exercise has been shown to be beneficial in the setting of several thyroid diseases. Physical activity and exercise programs have been shown to improve health-related QoL in patients with subclinical hypothyroidism [111]. In patients with hypothyroidism due to treatment of thyroid cancer, fatigue seems to be associated with decreased physical activity [112]. Physical activity also partially alleviates the fatigue in patients with thyroid cancer $[113,114]$. Given these considerations, it might be reasonable to consider a trial of standard of care LT4 versus LT4 and lifestyle changes, including exercise. However, this would be cumbersome for a combination therapy trial as placebo-controlled trials both with and without exercise would be necessary. For example, a $2 \times 2$ factorial design randomized controlled trial, randomizing patients to either combination therapy or LT4 and to either a lifestyle intervention (e.g., education, diet, exercise, or a combination) or no lifestyle intervention, could inform the understanding of pharmacological and nonpharmacological interventions and their effects on fatigue, cognition, and weight.

Combination Therapy Consensus

Statement
Summary statements

- Satisfaction with therapy for hypothyroidism is influenced by many additional patient-specific factors (e.g., adequate sleep, regular exercise, and weight management), in addition to their dose and type of TH therapy.

- Patient-directed knowledge translation research is needed to inform patients of the risks, benefits, and uncertainties related to the choice of thyroid hormone preparations, based on evidence available from published trials.

- Patients note the importance of open communication with their health care provider about their symptoms.

Topic 11: Applying Published ETA Guidelines on the Use of Combination LT4/LT3 Therapy in Clinical Practice in the Current State of Knowledge (Presenters at Live Conference: C.M.D., E.F., Topic Summarizer: C.M.D.)

\section{Which Patients to Consider and Not to Consider for \\ Combination Therapy}

Despite the negative results of the trials that have been published thus far, both patients and physicians remain interested in prescribing combination therapy [115-117]. The 2013 ETA guidelines advise considering combination therapy for patients with persistent symptoms despite adequate doses of LT4, after all other relevant comorbidities have been excluded [55]. The possibility of undiagnosed psychological comorbidities should also be considered. Based on our current knowledge, biochemical measures (e.g., rT3), genetics and neuropsychological testing do not seem to be valuable in patient selection. Patients who are pregnant or trying to conceive, or with arrythmias or established cardiovascular disease should not be considered.

\section{What Should Be Done Before Commencing a Trial of}

\section{Combination Therapy}

If a trial of combination therapy is being considered within an individual patient, it is important to set clear expectations [55]. These include explaining that this is a nonstandard treatment for which the risks are unclear with the potential for accelerated osteoporosis and atrial fibrillation with stroke risk. In addition, it should be made clear that this is a trial of a nonstandard therapy potentially with significant monetary cost [118], and treatment will be discontinued if no benefit is experienced with a reasonable time frame, such as 3-6 months. The requirements and importance of medication compliance and 
timing and compliance with follow-up should be emphasized.

\section{Which Medication}

A wide range of LT3 preparations are available with tablet strengths varying from 5 to $50 \mu \mathrm{g}$. The ETA guidelines recommend a starting ratio of 13:1 to 20:1 (LT4:LT3), which represents a dose of 5 or $10 \mu \mathrm{g}$ LT3 for patients taking 100-200 $\mu \mathrm{g}$ LT4 [55]. Cutting LT3 pills with a pill cutter would allow for twice-daily dosing such as $2.5 \mu \mathrm{g}$ twice daily. At the start, the LT4 dose is usually reduced by 12.5 or $25 \mu \mathrm{g}$ to accommodate the addition of LT3. The therapeutic substitution of LT3 for LT4 has previously been calculated to approximate a 1:3 ratio [76].

In theory, the ratio of T4:T3 of 13:1 to $20: 1$ could also be achieved by a combination of DTE and LT4, an approach that has been suggested by some patient groups, possibly based on the premise that there are additional salutary effects of DTE.

\section{Monitoring}

Monitoring is challenging due to the variation in serum T3 levels with current preparations. If peak serum T3 levels ( $2-4 \mathrm{~h}$ postdose) are within the reference range and TSH is not suppressed, this is likely to be a safe dose range, although not all patients are satisfied in this range. For patients in whom there is a long-term plan to continue LT3, pulse regularity and electrocardiogram monitoring for atrial fibrillation at each office visit along with 3-year bone densitometry in postmenopausal women would seem appropriate, although there are no data available to provide anything beyond an expert opinion.

\section{Assessment of Response and Long-Term Follow-Up}

Response is commonly assessed through patient selfreport of "improvement," though some clinics use questionnaires (e.g., ThyPRO). It is important to assess the response to be able to stop the treatment if it is not effective or if the effect is lost over time, based on PROs. It would, therefore, seem reasonable to continue to monitor patients on combination therapy until the picture is clearer with respect to long-term safety, by assessment for cardiac and skeletal side effects. The TEARS data [38] raised the possibility of increased breast cancer risk. It would, therefore, also seem reasonable to ensure that routine recommendations for mammograms are adhered to, especially in those with risk factors for breast cancer. Counseling patients before initiation of therapy regarding potential cardiac, bone density, and cancer progression risks should also be incorporated.

\section{Conclusion and Summary}

Based on the presentation and discussion of these topics by the authors, we believe that there is equipoise for a new well-designed adequately powered clinical trial of combination therapy. Furthermore, patients and physicians have demonstrated an urgent strong interest in addressing the clinical problem of patients' dissatisfaction with the existing standard of care for TH therapy. Additional physiological/translational data, informing the theoretical basis for potential combination therapy benefit, may be generated in parallel with planned or ongoing studies in order not to delay new studies in this area. Topics 1-10 review information that we believe will inform the design of future combination therapy studies.

For each of the 10 topics, Summary Statements were developed. In addition to the Summary Statements, Consensus Statements regarding clinical trial design were developed and voted upon as described in the methods. Table 1 lists the resulting Consensus Statements, some with $100 \%$ agreement, others with $75 \%$ or greater agreement, and a minority with $<75 \%$ agreement. All Consensus Statements are also given in online supplementary Table 7 along with some of the iterative comments of the authors to make the areas of agreement, discussion, and disagreement transparent and available for future discussions. These Consensus Statements with 75-100\% agreement present considerations arising from the symposium, and the subsequent synthesis of the material by the authors, which we believe should be considered for inclusion in the design of future studies of combination therapy. In the light of recent scientific developments, it is proposed that these changes to the design of previous studies may represent a substantial advance on achieving a fair assessment of the potential benefits of "physiological thyroid hormone replacement" using combination LT4/LT3 therapy, with a focus on assessment of its effects on patientcentered outcomes/PROs. The results of such clinical trials may differ from previous studies and could be of benefit to patients and will be of value to inform the treatment recommendations of future $\mathrm{TH}$ replacement clinical practice guidelines.
Jonklaas et al. 


\section{Acknowledgments}

The authors thank the ATA, BTA, and ETA for supporting and sponsoring the symposium on which this document is based. We thank the patient participants (formal speakers and audience members) who shared their perspectives in the symposium. Unrelated to this effort, LCM and HH were supported by Deutsche Forschungsgemeinschaft within CRC/TR 296 LocoTact; FSC was supported by the NIHNIDDK grant 1 R21 DK122310-01; JJ was supported by NIDCR grant 5R01DE025822-05.

\section{Conflict of Interest Statement}

J.J., A.R.C., H.H., E.A.M., L.C.M., A.M.S., and C.M.D. have no conflicts to discuss. A.C.B. is a consultant for Synthonics Inc., Allergan Inc., and BLA Technology LLC; F.S.C. is a consultant for IBSA and Acella; T.W. is a consultant for AbbVie, Allergan Inc., and developer of ThyPRO and ThyPRO-30. E.F. is a coinvestigator in a combination therapy trial funded by the Dutch government with funds provided to participating institutions (principal investigator [PI] Marco Medici). B.N. is the PI of a trial of synthetic combination therapy versus thyroid extract funded by the Danish government with funds provided to the institution. T.W. also serves as a volunteer consultant and steering committee member specifically with ThyPRO expertise for combination therapy trials with PIs Medici (above), B.N. (above), and Steen Bonnema (trial funded by the Danish government). C.M.D. serves as a volunteer external advisory board member for the trial with PI Medici (above).

\section{Funding Information}

No funding of any kind was provided for the development of this consensus statement.

\section{References}

1 Jonklaas J, Cappola AR, Celi FS. Editorial: Combination Therapy for Hypothyroidism: The Journey From Bench to Bedside. Front Endocrinol. 2020 Jun;11:422.

2 Escobar-Morreale HF, Obregón MJ, Escobar del Rey F, Morreale de Escobar G. Replacement therapy for hypothyroidism with thyroxine alone does not ensure euthyroidism in all tissues, as studied in thyroidectomized rats. J Clin Invest. 1995 Dec;96(6):2828-38.

3 Escobar-Morreale HF, del Rey FE, Obregón MJ, de Escobar GM. Only the combined treatment with thyroxine and triiodothyronine ensures euthyroidism in all tissues of the thyroidectomized rat. Endocrinology. 1996 Jun; 137(6):2490-502.

4 Werneck de Castro JP, Fonseca TL, Ueta CB, McAninch EA, Abdalla S, Wittmann G, et al. Differences in hypothalamic type 2 deiodinase ubiquitination explain localized sensitivity to thyroxine. J Clin Invest. 2015 Feb; 125(2):769-81.

5 Christoffolete MA, Ribeiro R, Singru P, Fekete C, da Silva WS, Gordon DF, et al. Atypical expression of type 2 iodothyronine deiodinase in thyrotrophs explains the thyroxinemediated pituitary thyrotropin feedback mechanism. Endocrinology. 2006 Apr; 147(4):1735-43.

6 Saberi M, Sterling FH, Utiger RD. Reduction in extrathyroidal triiodothyronine production by propylthiouracil in man. J Clin Invest. 1975 Feb;55(2):218-23.

7 Dentice M, Bandyopadhyay A, Gereben B, Callebaut I, Christoffolete MA, Kim BW, et al. The Hedgehog-inducible ubiquitin ligase subunit WSB-1 modulates thyroid hormone activation and PTHrP secretion in the developing growth plate. Nat Cell Biol. 2005 Jul; 7(7):698-705.
8 Larsen PR. Thyroid-pituitary interaction: feedback regulation of thyrotropin secretion by thyroid hormones. N Engl J Med. 1982 Jan; 306(1):23-32.

9 Jonklaas J, Bianco AC, Bauer AJ, Burman KD, Cappola AR, Celi FS, et al.; American Thyroid Association Task Force on Thyroid Hormone Replacement. Guidelines for the treatment of hypothyroidism: prepared by the american thyroid association task force on thyroid hormone replacement. Thyroid. 2014 Dec; 24(12):1670-751.

10 Jonklaas J, Davidson B, Bhagat S, Soldin SJ. Triiodothyronine levels in athyreotic individuals during levothyroxine therapy. JAMA. 2008 Feb;299(7):769-77.

11 Gullo D, Latina A, Frasca F, Le Moli R, Pellegriti G, Vigneri R. Levothyroxine monotherapy cannot guarantee euthyroidism in all athyreotic patients. PLoS One. 2011; 6(8):e22552.

12 Ito M, Miyauchi A, Morita S, Kudo T, Nishihara E, Kihara M, et al. TSH-suppressive doses of levothyroxine are required to achieve preoperative native serum triiodothyronine levels in patients who have undergone total thyroidectomy. Eur J Endocrinol. 2012 Sep; 167(3):373-8

13 Peterson SJ, McAninch EA, Bianco AC. Is a Normal TSH Synonymous With "Euthyroidism" in Levothyroxine Monotherapy? J Clin Endocrinol Metab. 2016 Dec;101(12):496473.

14 McAninch EA, Rajan KB, Miller CH, Bianco AC. Systemic Thyroid Hormone Status During Levothyroxine Therapy In Hypothyroidism: A Systematic Review and Meta-Analysis. J Clin Endocrinol Metab. 2018 Aug. https://doi.org/10.1210/jc.201801361.
15 Lee YK, Lee H, Han S, Jung H, Shin DY, Nam $\mathrm{KH}$, et al. Association between Thyroid-Stimulating Hormone Level after Total Thyroidectomy and Hypercholesterolemia in Female Patients with Differentiated Thyroid Cancer: A Retrospective Study. J Clin Med. 2019 Jul; 8(8):E1106

16 Ito M, Miyauchi A, Hisakado M, Yoshioka W, Ide A, Kudo T, Nishihara E, Kihara M, Ito Y, Kobayashi K, Miya A, Fukata S, Nishikawa M, Nakamura H, Amino N. Biochemical Markers Reflecting Thyroid Function in Athyreotic Patients on Levothyroxine Monotherapy. Thyroid. 2017;27(4):484-490.

17 Clyde PW, Harari AE, Getka EJ, Shakir KM. Combined levothyroxine plus liothyronine compared with levothyroxine alone in primary hypothyroidism: a randomized controlled trial. JAMA. 2003 Dec;290(22):2952-8.

18 Mentuccia D, Proietti-Pannunzi L, Tanner K, Bacci V, Pollin TI, Poehlman ET, et al. Association between a novel variant of the human type 2 deiodinase gene Thr92Ala and insulin resistance: evidence of interaction with the Trp64Arg variant of the beta-3-adrenergic receptor. Diabetes. 2002 Mar;51(3):880-3.

19 Castagna MG, Dentice M, Cantara S, Ambrosio R, Maino F, Porcelli T, et al. DIO2 Thr92Ala Reduces Deiodinase-2 Activity and SerumT3 Levels in Thyroid-Deficient Patients. J Clin Endocrinol Metab. 2017 May;102(5): 1623-30.

20 Jo S, Fonseca TL, Bocco BM, Fernandes GW, McAninch EA, Bolin AP, et al. Type 2 deiodinase polymorphism causes ER stress and hypothyroidism in the brain. J Clin Invest. 2019 Jan;129(1):230-45. 
21 Jo S, Fonseca TL, Bocco BM, Fernandes GW, McAninch EA, Bolin AP, et al. Type 2 deiodinase polymorphism causes ER stress and hypothyroidism in the brain. J Clin Invest. 2019 Jan;129(1):230-45.

22 Panicker V, Saravanan P, Vaidya B, Evans J, Hattersley AT, Frayling TM, et al. Common variation in the $\mathrm{DIO} 2$ gene predicts baseline psychological well-being and response to combination thyroxine plus triiodothyronine therapy in hypothyroid patients. J Clin Endocrinol Metab. 2009 May;94(5):1623-9.

23 Nygaard B, Jensen EW, Kvetny J, Jarløv A, Faber J. Effect of combination therapy with thyroxine (T4) and 3,5,3'-triiodothyronine versus T4 monotherapy in patients with hypothyroidism, a double-blind, randomised cross-over study. Eur J Endocrinol. 2009 Dec; 161(6):895-902.

24 Carlé A, Faber J, Steffensen R, Laurberg P, Nygaard B. Hypothyroid Patients Encoding Combined MCT10 and DIO2 Gene Polymorphisms May Prefer L-T3 + L-T4 Combination Treatment - Data Using a Blind, Randomized, Clinical Study. Eur Thyroid J. 2017 Jul;6(3): 143-51.

25 Wouters HJ, van Loon HC, van der Klauw MM, Elderson MF, Slagter SN, Kobold AM, Kema IP, Links TP, van Vliet-Ostaptchouk JV, Wolffenbuttel BH. No Effect of the Thr92Ala Polymorphism of Deiodinase- 2 on Thyroid Hormone Parameters, Health-Related Quality of Life, and Cognitive Functioning in a Large Population-Based Cohort Study. Thyroid. 2017;27(2):147-155.

26 Yen PM. Physiological and molecular basis of thyroid hormone action. Physiol Rev. 2001 Jul;81(3):1097-142.

27 Cheng SY, Leonard JL, Davis PJ. Molecular aspects of thyroid hormone actions. Endocr Rev. 2010 Apr;31(2):139-70.

28 Flamant F, Cheng SY, Hollenberg AN, Moeller LC, Samarut J, Wondisford FE, et al. Thyroid Hormone Signaling Pathways: Time for a More Precise Nomenclature. Endocrinology. 2017 Jul;158(7):2052-7.

29 Hönes GS, Rakov H, Logan J, Liao XH, Werbenko E, Pollard AS, et al. Noncanonical thyroid hormone signaling mediates cardiometabolic effects in vivo. Proc Natl Acad Sci USA. 2017 Dec;114(52):E11323-32.

30 Fabian ID, Rosner M, Fabian I, VishnevskiaDai V, Zloto O, Shinderman Maman E, et al. Low thyroid hormone levels improve survival in murine model for ocular melanoma. Oncotarget. 2015 May;6(13):11038-46.

31 Lee YS, Chin YT, Shih YJ, Nana AW, Chen YR, Wu HC, et al. Thyroid Hormone Promotes $\beta$-Catenin Activation and Cell Proliferation in Colorectal Cancer. Horm Cancer. 2018 Jun;9(3):156-65.

32 Latteyer S, Christoph S, Theurer S, Hönes GS, Schmid KW, Führer D, et al. Thyroxine promotes lung cancer growth in an orthotopic mouse model. Endocr Relat Cancer. 2019 Jun; 26(6):565-74.
33 Kannan L, Shaw PA, Morley MP, Brandimarto J, Fang JC, Sweitzer NK, et al. Thyroid Dysfunction in Heart Failure and Cardiovascular Outcomes. Circ Heart Fail. 2018 Dec; 11(12):e005266.

34 Ferrara AM, Onigata K, Ercan O, Woodhead H, Weiss RE, Refetoff S. Homozygous thyroid hormone receptor $\beta$-gene mutations in resistance to thyroid hormone: three new cases and review of the literature. J Clin Endocrinol Metab. 2012 Apr;97(4):1328-36.

35 Bruinstroop E, Dalan R, Cao Y, Bee YM, Chandran K, Cho LW, et al. Low-Dose Levothyroxine Reduces Intrahepatic Lipid Content in Patients With Type 2 Diabetes Mellitus and NAFLD. J Clin Endocrinol Metab. 2018 Jul;103(7):2698-706.

36 Kim HI, Kim M, Lee SH, Park SY, Kim YN, Kim H, et al. Development of thyroid dysfunction is associated with clinical response to PD-1 blockade treatment in patients with advanced non-small cell lung cancer. OncoImmunology. 2017 Sep;7(1):e1375642.

37 Moeller LC, Führer D. Thyroid hormone, thyroid hormone receptors, and cancer: a clinical perspective. Endocr Relat Cancer. 2013 Mar;20(2):R19-29.

38 Leese GP, Soto-Pedre E, Donnelly LA. Liothyronine use in a 17 year observational population-based study - the tears study. Clin Endocrinol. 2016 Dec;85(6):918-25.

39 Angelousi A, Diamanti-Kandarakis E, Zapanti E, Nonni A, Ktenas E, Mantzou A, et al. Is there an association between thyroid function abnormalities and breast cancer? Arch Endocrinol Metab. 2017 Jan-Feb;61(1):54-61.

40 Tran TV, Kitahara CM, de Vathaire F, Boutron-Ruault MC, Journy N. Thyroid dysfunction and cancer incidence: a systematic review and meta-analysis. Endocr Relat Cancer. 2020 Apr;27(4):245-59.

41 Groeneweg S, van Geest FS, Peeters RP, Heuer H, Visser WE. Thyroid Hormone Transporters. Endocr Rev. 2020 Apr;41(2):bnz008. https://doi.org/10.1210/endrev/bnz008.

42 Bernal J, Guadaño-Ferraz A, Morte B. Thyroid hormone transporters-functions and clinical implications. Nat Rev Endocrinol. 2015 Dec;11(12):690.

43 López-Espíndola D, Morales-Bastos C, Grijota-Martínez C, Liao XH, Lev D, Sugo E, et al. Mutations of the thyroid hormone transporter MCT8 cause prenatal brain damage and persistent hypomyelination. J Clin Endocri nol Metab. 2014 Dec;99(12):E2799-804.

44 van der Deure WM, Peeters RP, Visser TJ. Molecular aspects of thyroid hormone transporters, including MCT8, MCT10, and OATPs, and the effects of genetic variation in these transporters. J Mol Endocrinol. 2010 Jan;44(1):1-11.
45 van der Deure WM, Appelhof BC, Peeters RP, Wiersinga WM, Wekking EM, Huyser J, et al. Polymorphisms in the brain-specific thyroid hormone transporter OATP1C1 are associated with fatigue and depression in hypothyroid patients. Clin Endocrinol. 2008 Nov; 69(5):804-11

46 Bunevicius R, Kazanavicius G, Zalinkevicius $\mathrm{R}$, Prange AJ Jr. Effects of thyroxine as compared with thyroxine plus triiodothyronine in patients with hypothyroidism. N Engl J Med. 1999 Feb;340(6):424-9.

47 Saravanan P, Simmons DJ, Greenwood R, Peters TJ, Dayan CM. Partial substitution of thyroxine (T4) with tri-iodothyronine in patients on T4 replacement therapy: results of a large community-based randomized controlled trial. J Clin Endocrinol Metab. 2005 Feb;90(2): 805-12.

48 Valizadeh M, Seyyed-Majidi MR, Hajibeigloo H, Momtazi S, Musavinasab N, Hayatbakhsh MR. Efficacy of combined levothyroxine and liothyronine as compared with levothyroxine monotherapy in primary hypothyroidism: a randomized controlled trial. Endocr Res. 2009;34(3):80-9.

49 Escobar-Morreale HF, Botella-Carretero JI, Gómez-Bueno M, Galán JM, Barrios V, Sancho J. Thyroid hormone replacement therapy in primary hypothyroidism: a randomized trial comparing L-thyroxine plus liothyronine with L-thyroxine alone. Ann Intern Med. 2005 Mar; 142(6):412-24.

50 Escobar-Morreale HF, Botella-Carretero JI, Gómez-Bueno M, Galán JM, Barrios V, Sancho J. Thyroid hormone replacement therapy in primary hypothyroidism: a randomized trial comparing L-thyroxine plus liothyronine with L-thyroxine alone. Ann Intern Med. 2005 Mar;142(6):412-24.

51 Bunevicius R, Jakuboniene N, Jurkevicius R, Cernicat J, Lasas L, Prange AJ Jr. Thyroxine vs thyroxine plus triiodothyronine in treatment of hypothyroidism after thyroidectomy for Graves' disease. Endocrine. $2002 \mathrm{Jul} ; 18(2)$ : 129-33.

52 Walsh JP, Shiels L, Lim EM, Bhagat CI, Ward LC, Stuckey BG, et al. Combined thyroxine/ liothyronine treatment does not improve well-being, quality of life, or cognitive function compared to thyroxine alone: a randomized controlled trial in patients with primary hypothyroidism. J Clin Endocrinol Metab. 2003 Oct; $88(10): 4543-50$.

53 Appelhof BC, Fliers E, Wekking EM, Schene AH, Huyser J, Tijssen JG, et al. Combined therapy with levothyroxine and liothyronine in two ratios, compared with levothyroxine monotherapy in primary hypothyroidism: a double-blind, randomized, controlled clinical trial. J Clin Endocrinol Metab. 2005 May; 90(5):2666-74.

54 Akirov A, Fazelzad R, Ezzat S, Thabane L, Sawka AM. A Systematic Review and Meta-Analysis of Patient Preferences for Combination Thyroid Hormone Treatment for Hypothyroidism. Front Endocrinol. 2019 Jul;10:477. 
55 Wiersinga WM, Duntas L, Fadeyev V, Nygaard B, Vanderpump MP. 2012 ETA Guidelines: The Use of L-T4 + L-T3 in the Treatment of Hypothyroidism. Eur Thyroid J. 2012 Jul;1(2):55-71.

56 Samuels MH, Schuff KG, Carlson NE, Carello $P$, Janowsky JS. Health status, mood, and cognition in experimentally induced subclinical thyrotoxicosis. J Clin Endocrinol Metab. 2008 May;93(5):1730-6.

57 Saravanan P, Siddique H, Simmons DJ, Greenwood R, Dayan CM. Twenty-four hour hormone profiles of TSH, Free T3 and free T4 in hypothyroid patients on combined T3/T4 therapy. Exp Clin Endocrinol Diabetes. 2007 Apr;115(4):261-7.

58 Hoang TD, Olsen CH, Mai VQ, Clyde PW, Shakir MK. Desiccated thyroid extract compared with levothyroxine in the treatment of hypothyroidism: a randomized, doubleblind, crossover study. J Clin Endocrinol Metab. 2013 May;98(5):1982-90.

59 Rodriguez T, Lavis VR, Meininger JC, Kapadia AS, Stafford LF. Substitution of liothyronine at a 1:5 ratio for a portion of levothyroxine: effect on fatigue, symptoms of depression, and working memory versus treatment with levothyroxine alone. Endocr Pract. 2005; 11(4):223-233.

60 Sawka AM, Gerstein HC, Marriott MJ, MacQueen GM, Joffe RT. Does a combination regimen of thyroxine (T4) and 3,5,3' -triiodothyronine improve depressive symptoms better than T4 alone in patients with hypothyroidism? Results of a double-blind, randomized, controlled trial. J Clin Endocrinol Metab. 2003 Oct;88(10):4551-5.

61 Data from: https://www.nice.org.uk/guidance/ng145/evidence

62 Jaeschke R, Guyatt G, Cook D, Harper S, Gerstein HC. Spectrum of quality of life impairment in hypothyroidism. Qual Life Res. 1994 Oct;3(5):323-7.

63 Saravanan P, Chau WF, Roberts N, Vedhara K, Greenwood R, Dayan CM. Psychological well-being in patients on 'adequate' doses of l-thyroxine: results of a large, controlled community-based questionnaire study. Clin Endocrinol. 2002 Nov;57(5):577-85.

64 Watt T, Bjorner JB, Groenvold M, Rasmussen AK, Bonnema SJ, Hegedüs L, et al. Establishing construct validity for the thyroid-specific patient reported outcome measure (ThyPRO): an initial examination. Qual Life Res. 2009 May; 18(4):483-96.

65 Razvi S, McMillan CV, Weaver JU. Instruments used in measuring symptoms, health status and quality of life in hypothyroidism: a systematic qualitative review. Clin Endocrinol. 2005 Dec;63(6):617-24.

66 Winther KH, Cramon P, Watt T, Bjorner JB, Ekholm O, Feldt-Rasmussen U, et al. DiseaseSpecific as Well as Generic Quality of Life Is Widely Impacted in Autoimmune Hypothyroidism and Improves during the First Six Months of Levothyroxine Therapy. PLoS One. 2016 Jun;11(6):e0156925.
67 DiStefano J 3rd, Jonklaas J. Predicting Optimal Combination LT4 + LT3 Therapy for Hypothyroidism Based on Residual Thyroid Function. Front Endocrinol. 2019 Nov;10: 746.

68 Medici BB, la Cour JL, Michaelsson LF, Faber JO, Nygaard B. Neither Baseline nor Changes in Serum Triiodothyronine during Levothyroxine/Liothyronine Combination Therapy Predict a Positive Response to This Treatment Modality in Hypothyroid Patients with Persistent Symptoms. Eur Thyroid J. 2017 Apr; 6(2):89-93.

69 Guldvog I, Reitsma LC, Johnsen L, Lauzike A, Gibbs C, Carlsen E, et al. Thyroidectomy Versus Medical Management for Euthyroid Patients With Hashimoto Disease and Persisting Symptoms: A Randomized Trial. Ann Intern Med. 2019 Apr;170(7):453-64.

70 Jonklaas J, Davidson B, Bhagat S, Soldin SJ. Triiodothyronine levels in athyreotic individuals during levothyroxine therapy. JAMA. 2008 Feb;299(7):769-77.

71 Siegmund W, Spieker K, Weike AI, Giessmann T, Modess C, Dabers T, et al. Replacement therapy with levothyroxine plus triiodothyronine (bioavailable molar ratio 14:1) is not superior to thyroxine alone to improve well-being and cognitive performance in hypothyroidism. Clin Endocrinol. 2004 Jun; 60(6):750-7.

72 Araque KA, Klubo-Gwiezdzinska J, Nieman LK, Welsh K, Soldin SJ. Assessment of thyroid function tests and harmonization: opinion on thyroid hormone harmonization. Ther Adv Endocrinol Metab. 2019 Dec; 10: 2042018819897049.

73 Lartey LJ, Werneck-de-Castro JP, O-Sullivan I, Unterman TG, Bianco AC. Coupling between Nutrient Availability and Thyroid Hormone Activation. J Biol Chem. 2015 Dec; 290(51):30551-61.

74 Jonklaas J, Burman KD. Daily Administration of Short-Acting Liothyronine Is Associated with Significant Triiodothyronine Excursions and Fails to Alter Thyroid-Responsive Parameters. Thyroid. 2016;26(6):770-778.

75 Celi FS, Zemskova M, Linderman JD, Smith S, Drinkard B, Sachdev V, et al. Metabolic effects of liothyronine therapy in hypothyroidism: a randomized, double-blind, crossover trial of liothyronine versus levothyroxine. J Clin Endocrinol Metab. 2011 Nov;96(11): 3466-74.

76 Celi FS, Zemskova M, Linderman JD, Babar NI, Skarulis MC, Csako G, et al. The pharmacodynamic equivalence of levothyroxine and liothyronine: a randomized, double blind, cross-over study in thyroidectomized patients. Clin Endocrinol. 2010 May;72(5):70915.

77 Van Tassell B, Wohlford GF 4th, Linderman JD, Smith S, Yavuz S, Pucino F, et al. Pharmacokinetics of L-Triiodothyronine in Patients Undergoing Thyroid Hormone Therapy Withdrawal. Thyroid. 2019 Oct;29(10):13719.
78 Fadeyev VV, Morgunova TB, Melnichenko GA, Dedov II. Combined therapy with L-thyroxine and L-triiodothyronine compared to L-thyroxine alone in the treatment of primary hypothyroidism. Hormones. 2010 Jul-Sep; 9(3):245-52.

79 Kaminski J, Miasaki FY, Paz-Filho G, Graf H, Carvalho GA. Treatment of hypothyroidism with levothyroxine plus liothyronine: a randomized, double-blind, crossover study. Arch Endocrinol Metab. 2016 Nov-Dec;60(6):56272.

80 Idrees T, Price JD, Piccariello T, Bianco AC. Sustained Release T3 Therapy: Animal Models and Translational Applications. Front Endocrinol. 2019 Aug;10:544.

81 Santini F, Ceccarini G, Pelosini C, Giannetti M, Ricco I, Querci G, et al. Treatment of Hypothyroid Patients With L-Thyroxine (L-T4) Plus Triiodothyronine Sulfate (T3S). A Phase II, Open-Label, Single Center, Parallel Groups Study on Therapeutic Efficacy and Tolerability. Front Endocrinol. 2019 Nov; 10:826.

82 Santini F, Giannetti M, Ricco I, Querci G, Saponati G, Bokor D, et al. Steady-State Serum T3 Concentrations for 48 Hours Following the Oral Administration of a Single Dose of 3,5,3'-Triiodothyronine Sulfate (T3S). Endocr Pract. 2014 Jul;20(7):680-9.

83 Hennemann G, Docter R, Visser TJ, Postema PT, Krenning EP. Thyroxine plus low-dose, slow-release triiodothyronine replacement in hypothyroidism: proof of principle. Thyroid. 2004;14(4):271-275.

84 Ettleson MD, Bianco AC. Individualized Therapy for Hypothyroidism: Is T4 Enough for Everyone? J Clin Endocrinol Metab. 2020 Sep;105(9):dgaa430.

85 Midgley JE, Toft AD, Larisch R, Dietrich JW, Hoermann R. Time for a reassessment of the treatment of hypothyroidism. BMC Endocr Disord. 2019 Apr;19(1):37.

86 Fitzgerald SP, Bean NG, Falhammar H, Tuke J. Clinical parameters are more likely to be associated with thyroid hormone levels than with TSH levels: a systematic review and meta-analysis. Thyroid Jun 4 doi: https://doi. org/101089/thy20190535.. Online ahead of print. 2020

87 Taylor PN, Sayers A, Okosieme O, Das G, Draman MS, Tabasum A, et al. Maturation in Serum Thyroid Function Parameters Over Childhood and Puberty: Results of a Longitudinal Study. J Clin Endocrinol Metab. 2017 Jul;102(7):2508-15.

88 Andersen S, Pedersen KM, Bruun NH, Laurberg P. Narrow individual variations in serum $\mathrm{T}(4)$ and $\mathrm{T}(3)$ in normal subjects: a clue to the understanding of subclinical thyroid disease. J Clin Endocrinol Metab. 2002 Mar;87(3): 1068-72.

89 Wiersinga WM. T4 + T3 combination therapy: any progress? Endocrine. 2019 Oct;66(1): $70-8$. 
90 Revicki DA, Osoba D, Fairclough D, Barofsky I, Berzon R, Leidy NK, et al. Recommendations on health-related quality of life research to support labeling and promotional claims in the United States. Qual Life Res. 2000;9(8): 887-900.

91 Watt T, Hegedüs L, Rasmussen AK, Groenvold $\mathrm{M}$, Bonnema SJ, Bjorner JB, et al. Which domains of thyroid-related quality of life are most relevant? Patients and clinicians provide complementary perspectives. Thyroid. 2007 Jul;17(7):647-54.

92 Watt T. Measuring impact of benign thyroid diseases on quality of life. In: Caplan M, editor. Reference Module in Biomedical Sciences. Amsterdam: Elsevier; 2018.

93 Wong CK, Lang BH, Lam CL. A systematic review of quality of thyroid-specific healthrelated quality-of-life instruments recommends ThyPRO for patients with benign thyroid diseases. J Clin Epidemiol. 2016 Oct;78: 63-72.

94 Watt T, Hegedüs L, Groenvold M, Bjorner JB, Rasmussen AK, Bonnema SJ, et al. Validity and reliability of the novel thyroid-specific quality of life questionnaire, ThyPRO. Eur J Endocrinol. 2010 Jan;162(1):161-7.

95 Watt T, Cramon P, Hegedüs L, Bjorner JB, Bonnema SJ, Rasmussen ÅK, et al. The thyroid-related quality of life measure ThyPRO has good responsiveness and ability to detect relevant treatment effects. J Clin Endocrinol Metab. 2014 Oct;99(10):3708-17.

96 Watt T, Groenvold M, Deng N, Gandek B, Feldt-Rasmussen $U$, Rasmussen $\AA K$, et al. Confirmatory factor analysis of the thyroidrelated quality of life questionnaire ThyPRO. Health Qual Life Outcomes. 2014 Sep;12(1): 126.

97 Watt T, Groenvold M, Hegedüs L, Bonnema SJ, Rasmussen ÅK, Feldt-Rasmussen U, et al. Few items in the thyroid-related quality of life instrument ThyPRO exhibited differential item functioning. Qual Life Res. 2014 Feb; 23(1):327-38.

98 Watt T, Bjorner JB, Groenvold M, Cramon P, Winther KH, Hegedüs L, et al. Development of a Short Version of the Thyroid-Related Patient-Reported Outcome ThyPRO. Thyroid. 2015 Oct;25(10):1069-79.

99 Ruta DA, Garratt AM, Leng M, Russell IT, MacDonald LM. A new approach to the measurement of quality of life. The Patient-Generated Index. Med Care. 1994 Nov;32(11): 1109-26.
100 O’Boyle CA, Hickey A, Joyce CR, O’Malley K, Hiltbrunner B. Evaluation of Individual Quality of Life (SEIQoL). Administration manual. Dublin: Royal College of Surgeons in Ireland; 1993. pp. 1-73. https://repository.rcsi.com/articles/The_Schedule_for the_Evaluation_of_Individual_Quality_of_ Life_SEIQoL_Administration_Manual_/10770242

101 Peterson SJ, Cappola AR, Castro MR, Dayan CM, Farwell AP, Hennessey JV, et al. An Online Survey of Hypothyroid Patients Demonstrates Prominent Dissatisfaction. Thyroid. 2018 Jun;28(6):707-21.

102 Reeve BB, Wyrwich KW, Wu AW, Velikova G, Terwee CB, Snyder CF, et al. ISOQOL recommends minimum standards for patient-reported outcome measures used in patient-centered outcomes and comparative effectiveness research. Qual Life Res. 2013 Oct;22(8):1889-905.

103 Michaelsson LF, la Cour JL, Medici BB, Watt T, Faber J, Nygaard B. Levothyroxine/Liothyronine Combination Therapy and Quality of Life: Is It All about Weight Loss? Eur Thyroid J. 2018 Oct;7(5):243-50.

104 Jonklaas J. Risks and safety of combination therapy for hypothyroidism. Expert Rev Clin Pharmacol. 2016 Aug;9(8):1057-67.

105 Weintraub S, Dikmen SS, Heaton RK, Tulsky DS, Zelazo PD, Bauer PJ, et al. Cognition assessment using the NIH Toolbox. Neurology. 2013 Mar;80(11 Suppl 3):S54-64.

106 Heaton RK, Akshoomoff N, Tulsky D, Mungas D, Weintraub S, Dikmen S, et al. Reliability and validity of composite scores from the NIH Toolbox Cognition Battery in adults. J Int Neuropsychol Soc. 2014 Jul; 20(6):588-98.

107 Siegmund W, Spieker K, Weike AI, Giessmann T, Modess C, Dabers T, et al. Replacement therapy with levothyroxine plus triiodothyronine (bioavailable molar ratio $14: 1$ ) is not superior to thyroxine alone to improve well-being and cognitive performance in hypothyroidism. Clin Endocrinol. 2004 Jun; 60(6):750-7

108 Toloza FJ, Espinoza Suarez NR, El Kawkgi O, Golembiewski EH, Ponce OJ, Yao L, et al. Patient Experiences and Perceptions Associated with the Use of Desiccated Thyroid Extract. Medicina. 2020 Apr;56(4):E161.
109 Louwerens M, Appelhof BC, Verloop H Medici M, Peeters RP, Visser TJ, et al. Fatigue and fatigue-related symptoms in patients treated for different causes of hypothyroidism. Eur J Endocrinol. 2012 Dec 167(6):809-15.

110 Taylor PN, Albrecht D, Scholz A, GutierrezBuey G, Lazarus JH, Dayan CM, et al. Global epidemiology of hyperthyroidism and hypothyroidism. Nat Rev Endocrinol. 2018 May;14(5):301-16.

111 Werneck FZ, Coelho EF, Almas SP, Garcia MM, Bonfante HL, Lima JR, et al. Exercise training improves quality of life in women with subclinical hypothyroidism: a randomized clinical trial. Arch Endocrinol Metab. 2018 Oct;62(5):530-6.

112 Alhashemi A, Jones JM, Goldstein DP, Mina DS, Thabane L, Sabiston CM, et al. An Exploratory Study of Fatigue and Physical Activity in Canadian Thyroid Cancer Patients. Thyroid. 2017 Sep;27(9):1156-63.

113 Vigário PS, Chachamovitz DS, Teixeira PF, Rocque ML, Santos ML, Vaisman M. Exercise is associated with better quality of life in patients on TSH-suppressive therapy with levothyroxine for differentiated thyroid carcinoma. Arq Bras Endocrinol Metabol. 2014 Apr;58(3):274-81.

114 Vigário PS, Chachamovitz DS, Cordeiro MF, Teixeira PF, de Castro CL, de Oliveira FP, et al. Effects of physical activity on body composition and fatigue perception in patients on thyrotropin-suppressive therapy for differentiated thyroid carcinoma. Thyroid. 2011 Jul;21(7):695-700.

115 Jonklaas J, Tefera E, Shara N. Short-Term Time Trends in Prescribing Therapy for Hypothyroidism: Results of a Survey of American Thyroid Association Members. Front Endocrinol. 2019 Jan;10:31.

116 Jonklaas J, Tefera E, Shara N. Prescribing Therapy for Hypothyroidism: Influence of Physician Characteristics. Thyroid. 2019 Jan;29(1):44-52.

117 Jonklaas J, Tefera E, Shara N. Physician Choice of Hypothyroidism Therapy: Influence of Patient Characteristics. Thyroid. 2018 Nov;28(11):1416-24.

118 Taylor PN, Razvi S, Muller I, Wass J, Dayan $\mathrm{CM}$, Chatterjee $\mathrm{K}$, et al. Liothyronine cost and prescriptions in England. Lancet Diabetes Endocrinol. 2019 Jan;7(1):11-2. 